\title{
Ionic Mechanism Underlying Rebound Depolarization in Medial Prefrontal Cortex Pyramidal Neurons
}

OPEN ACCESS

Edited by:

Marco Martina,

Northwestern University,

United States

Reviewed by:

Lia Forti,

University of Insubria, Italy

De-Lai Qiu,

Yanbian University, China

*Correspondence:

Przemysław Kurowski przemyslaw.kurowski@gmail.com

Paweł Szulczyk

pawel.szulczyk@wum.edu.pl

Received: 03 January 2018 Accepted: 21 March 2018

Published: 23 April 2018

Citation:

Kurowski P, Grzelka K and Szulczyk P (2018) lonic Mechanism Underlying

Rebound Depolarization in Medial Prefrontal Cortex Pyramidal Neurons.

Front. Cell. Neurosci. 12:93. doi: 10.3389/fncel.2018.00093

\author{
Przemysław Kurowski*, Katarzyna Grzelka and Paweł Szulczyk* \\ Laboratory of Physiology and Pathophysiology, Center for Preclinical Research and Technology, The Medical University of \\ Warsaw, Warsaw, Poland
}

Rebound depolarization (RD) occurs after membrane hyperpolarization and converts an arriving inhibitory signal into cell excitation. The purpose of our study was to clarify the ionic mechanism of RD in synaptically isolated layer $\mathrm{V}$ medial prefrontal cortex (mPFC) pyramidal neurons in slices obtained from 58- to 62-day-old male rats. The RD was evoked after a step hyperpolarization below $-80 \mathrm{mV}$, longer than $150 \mathrm{~ms}$ in 192 of 211 (91\%) tested neurons. The amplitude of RD was $30.6 \pm 1.2 \mathrm{mV}$ above the resting membrane potential $(-67.9 \pm 0.95 \mathrm{mV})$, and it lasted a few $100 \mathrm{~ms}(n=192)$. RD could be observed only after preventing BK channel activation, which was attained either by using paxilline, by removal of $\mathrm{Ca}^{++}$from the extra- or intracellular solution, by blockade of $\mathrm{Ca}^{++}$channels or during protein kinase $\mathrm{C}(\mathrm{PKC})$ activation. $\mathrm{RD}$ was resistant to tetrodotoxin (TTX) and was abolished after the removal of $\mathrm{Na}^{+}$from the extracellular solution or application of an anti-Nav1.9 antibody to the cell interior. We conclude that two membrane currents are concomitantly activated after the step hyperpolarization in the tested neurons: a. a low-threshold, TTX-resistant, $\mathrm{Na}^{+}$current that evokes RD; and b. an outward $\mathrm{K}^{+}$current through $\mathrm{BK}$ channels that opposes $\mathrm{Na}^{+}$-dependent depolarization. The obtained results also suggest that a. low-level $\mathrm{Ca}^{++}$in the external medium attained upon intense neuronal activity may facilitate the formation of RD and seizures; and b. RD can be evoked during the activation of PKC, which is an effector of a number of transduction pathways.

\section{Keywords: amyloid $\beta$-peptide (1-42), BK channels, $\mathrm{Ca}^{++}$channels, Nav1.9 channels, prefrontal cortex, pyramidal neurons, rats, rebound depolarization}

\section{INTRODUCTION}

The prefrontal cortex fulfills important cognitive functions, including mental set-shifting, inhibition, working memory, information updating, response monitoring and temporal coding (Szczepanski and Knight, 2014). Damage to the prefrontal function has been implicated in widespread illnesses, such as anxiety and depression (Albert et al., 2014), schizophrenia (Schubert et al., 2015), addiction (Volkow et al., 2016) and senile dementia (Kirshner, 2014). These neuropsychiatric disorders are likely to be caused by abnormal function or prefrontal cortex neurons and prefrontal cortex neural circuits.

Rebound depolarization (RD) is the membrane depolarization that occurs following hyperpolarization in neurons. If $\mathrm{RD}$ exceeds a threshold of voltage-dependent $\mathrm{Na}^{+}$currents, 
rebound excitation, a series of action potentials at RD peak, is evoked (Grenier et al., 1998; Tennigkeit et al., 1998; Fan et al., 2000; Sivaramakrishnan and Oliver, 2001; Timofeev et al., 2002; O'Donnell, 2003; Zheng and Raman, 2009; Boehme et al., 2011). RD is thought to be a mechanism responsible for converting an arriving inhibitory signal into cell excitation, which is subsequently synaptically transmitted to other neurons (Sanchez-Vives and McCormick, 2000). The cell hyperpolarization followed by $\mathrm{RD}$ can be elicited synaptically, such as by augmented GABAergic inhibitory synaptic input (Yu et al., 2004) or by hyperpolarizing current injection into the cell (Sanchez-Vives and McCormick, 2000).

RD depends primarily on the intrinsic properties of the neuron and relies on hyperpolarization-dependent de-inactivation or activation of channel currents. Numerous mechanisms, including the de-inactivation of T-type $\mathrm{Ca}^{++}$ channels (Boehme et al., 2011) or persistent $\mathrm{Na}^{+}$channels (Sangrey and Jaeger, 2010), the increased availability of $\mathrm{Na}^{+}$ (Aman and Raman, 2007) or high-threshold $\mathrm{Ca}^{++}$(Zheng and Raman, 2009) channels, and the activation of hyperpolarizationactivated cyclic nucleotide-gated (HCN) channels (Van Hook and Berson, 2010), have been proposed to mediate RD. The possibility that two or more channels are responsible for $\mathrm{RD}$ cannot be excluded (Engbers et al., 2013a).

$\mathrm{RD}$ has been implicated in the rhythmic discharges and oscillations that occur in neurons, such as during sleep (Wang et al., 1995), locomotor activity (Li and Moult, 2012), and epilepsy (Timofeev et al., 1998; Surges et al., 2006). RD can be recorded in various types of cells neurons, including deep cerebellar nuclei (Boehme et al., 2011), thalamic (Lüthi et al., 1998) and hippocampal (Surges et al., 2006). Hyperpolarization followed by $\mathrm{RD}$ has been suggested to facilitate the presence of a bistable behavior in medial prefrontal cortex (mPFC) pyramidal neurons, in which the membrane potential shifts from a down-state (negative membrane potential) to an up-state (positive membrane potential; Gulledge and Jaffe, 1998; Valenti and Grace, 2009; Marzo et al., 2014). Up-states in mPFC pyramidal neurons appear as prolonged depolarizations with persistent activity at the depolarization peak (Branchereau et al., 1996; Shu et al., 2003). Up- and down-states are also widely observed in cortical neurons (Harris and Thiele, 2011; Neske, 2016).

The purpose of our study was to determine the intrinsic mechanism responsible for $\mathrm{RD}$ in synaptically isolated layer $\mathrm{V}$ mPFC pyramidal neurons.

\section{MATERIALS AND METHODS}

The study was performed in accordance with the guidelines for the care and handling of laboratory animals in Directive 2010/63/EU of the European Parliament and of the Council and adhered to the national (Official Journal of Laws of 2015, item 266) and local (First Local Ethics Committee for Animal Experimentation in Warsaw) guidelines for the ethical use of animals. The Local Commission for the Well-Being of Animals in Warsaw monitored the experiments (Official Journal of The European Union on 20.10.2010, L276/72 (EN) ANNEX IV,
Methods of killing animals, Table 3, states that decapitation is allowed in rodents to kill animals for scientific purposes).

\section{Slice Preparation}

The experiments were performed on the neurons of 72 adult (58-62 days old) male Wistar rats obtained from a local animal facility. The applied experimental procedures were similar to those used in our recent studies (Kurowski et al., 2015; Szulczyk, 2016; Gawlak et al., 2017; Grzelka et al., 2017). Rats were decapitated, and their brains were removed and placed in cold $\left(0-4^{\circ} \mathrm{C}\right)$ extracellular solution containing the following (in $\mathrm{mM}$ ): $125 \mathrm{NaCl}, 25 \mathrm{NaHCO}_{3}, 3 \mathrm{KCl}, 1.25 \mathrm{NaH}_{2} \mathrm{PO}_{4}$, $0.5 \mathrm{CaCl}_{2}, 6 \mathrm{MgCl}_{2}$, and 25 glucose (bubbled with $95 \%$ $\mathrm{O}_{2} / 5 \% \mathrm{CO}_{2}$ ). Coronal slices (300- $\mu \mathrm{m}$ thick) containing the prefrontal cortex were prepared using a vibratome (Vibratome Line, Leica VT1200S, Nussloch, Germany). The slices were incubated for $7 \mathrm{~min}$ in warm $\left(34^{\circ} \mathrm{C}\right)$ extracellular solution containing the following (in $\mathrm{mM}$ ): $125 \mathrm{NaCl}, 25 \mathrm{NaHCO}_{3}, 3 \mathrm{KCl}$, $1.25 \mathrm{NaH}_{2} \mathrm{PO}_{4}, 1 \mathrm{CaCl}_{2}, 1 \mathrm{MgCl}_{2}$ and 25 glucose (bubbled with $95 \% \mathrm{O}_{2} / 5 \% \mathrm{CO}_{2}$ ). The osmolality was $320-330 \mathrm{mOsm} / \mathrm{kg}$ $\mathrm{H}_{2} \mathrm{O}$ and was adjusted with glucose. Then, the slices were incubated at room temperature in the same extracellular solution for at least $60 \mathrm{~min}$ before being transferred to the recording chamber.

\section{Patch-Clamp Recordings}

The slices were transferred to a bath chamber (RC-24E, Warner Instruments, LLC, Hamden, MA, USA) on the stage of an upright microscope (BX51WI, Olympus Corporation, Tokyo, Japan). During recording, the slices were perfused with warm $\left(34^{\circ} \mathrm{C}\right)$ extracellular solution containing the following (in $\mathrm{mM}$ ): $125 \mathrm{NaCl}, 25 \mathrm{NaHCO}_{3}, 3 \mathrm{KCl}, 1.25 \mathrm{NaH}_{2} \mathrm{PO}_{4}$, $1 \mathrm{CaCl}_{2}, 1 \mathrm{MgCl}_{2}$, and 25 glucose (bubbled with $95 \% \mathrm{O}_{2} / 5 \%$ $\mathrm{CO}_{2}$ ). In some cases, the $\mathrm{NaCl}$ in the extracellular solution was replaced with an equimolar concentration of choline- $\mathrm{Cl}$ (125 $\mathrm{mM})$ or $\mathrm{LiCl}(125 \mathrm{mM})$. When a nonselective $\mathrm{Ca}^{++}$ channel blocker was applied $\left(\mathrm{Cd}^{++}\right), \mathrm{NaH}_{2} \mathrm{PO}_{4}$ was removed from the extracellular solution. In several experiments, $\mathrm{Ca}^{++}$ was removed from the extracellular solution. In some cases, the $\mathrm{Ca}^{++}$concentration in the bath was 0.1 or $0.3 \mathrm{mM}$, as indicated in the text. To eliminate synaptic inputs, the extracellular solution was supplemented with blockers of glutamatergic (50 $\mu \mathrm{M}$, DL-2-amino-5-phosphonopentanoic acid, DL-AP5; $10 \mu \mathrm{M}$, 6,7-dinitroquinoxaline-2,3-dione, DNQX) or GABAergic transmission $(50 \mu \mathrm{M}$, picrotoxin) and a blocker of voltage-dependent $\mathrm{Na}^{+}$currents $(0.5 \mu \mathrm{M}$, tetrodotoxin, TTX).

Recordings were obtained from pyramidal neurons located $600-800 \mu \mathrm{m}$ from the cortical surface. This area of the mPFC corresponds to layer $\mathrm{V}$ pyramidal neurons in 58to 62-day-old rats (Gawlak et al., 2017). The neurons were observed via differential interference contrast microscopy using a $40 \times$ water-immersion objective, a camera (C7500-51), and a camera controller (C2741-62) from Hamamatsu Photonics K.K. (Hamamatsu City, Japan). The neurons chosen for the recordings had a triangular body shape and a characteristic apical dendrite. The recordings were obtained from 211 neurons located in 211 slices. 
The current-clamp recordings were obtained in a whole-cell configuration using a Multiclamp 700B amplifier, a Digidata 1440A digitizer, and pClamp 10.6 software (Molecular Devices, Sunnyvale, CA, USA). The pipettes were filled with intracellular solution containing the following (in $\mathrm{mM}$ ): 110 potassium gluconate, $20 \mathrm{KCl}, 0.5 \mathrm{EGTA}, 2 \mathrm{MgCl}_{2}, 2 \mathrm{Na}_{2}$-ATP, $0.4 \mathrm{GTP}$, 10 HEPES, and $5 \mathrm{NaCl}$ ( $\mathrm{pH} \mathrm{7.4,} \mathrm{osmolality} 280 \mathrm{mOsm} / \mathrm{kg}$ $\mathrm{H}_{2} \mathrm{O}$ ). In some experiments, the pipette solution also contained normal guinea pig $\operatorname{IgG}(4 \mu \mathrm{g} / \mathrm{ml})$, an antibody against Nav1.9 channels $(4 \mu \mathrm{g} / \mathrm{ml})$, the chelator BAPTA $(100 \mu \mathrm{M})$ or EGTA $(10 \mathrm{mM})$, or an amyloid $\beta$-peptide (1-42) $\left(\mathrm{A} \beta_{1-42}, 10 \mu \mathrm{M}\right)$. In some experiments, $20 \mathrm{mM}$ of $\mathrm{KCl}$ was replaced with $20 \mathrm{mM}$ of $\mathrm{KF}$ in the pipette solution.

The open-tip pipette resistance was 4-5 M $\Omega$. The pipette offset potential was zeroed when the pipette tip was dipped into the bath solution. Bridge balance and capacitance neutralization were carefully adjusted before and after every experimental protocol using the utility of the amplifier. After giga-seal formation, the cell membrane was disrupted by suction, and the membrane potential was recorded. The pipettes were formed from borosilicate glass with a filament (O.D.: $1.5 \mathrm{~mm}$, I.D.: $0.86 \mathrm{~mm}$; Sutter Instrument, Novato, CA, USA) using a P-1000 puller (Sutter Instrument, Novato, CA, USA). The membrane potential recordings were low-pass filtered at $1-3 \mathrm{kHz}$ and were digitized at a sampling rate of $10 \mathrm{kHz}$.

Hyperpolarizing current steps ( -20 and -40 pA, $200 \mathrm{~ms}$ ) were used to estimate passive properties, such as input resistance $\left(R_{\text {in }}\right)$, series resistance $\left(R_{\mathrm{S}}\right)$, and cell membrane capacitance $(\mathrm{C})$, of the tested pyramidal neurons. $R_{\mathrm{in}}$ and $R_{\mathrm{s}}$ were calculated as the slope of the linear fit of the current-voltage (I-V) relationship of either the steady-state current $\left(R_{\mathrm{in}}\right)$ or the instantaneous current $\left(R_{\mathrm{s}}\right)$. The time constant of the current relaxation $\left(\tau_{\mathrm{m}}\right)$ was estimated with a mono-exponential fit of the voltage response after a current step of $-40 \mathrm{pA}$. Cell capacitance was calculated from $R_{\mathrm{s}}$ and $\tau_{\mathrm{m}}$ according to the equation given by Marty and Neher (1995).

\section{Chemical Compounds}

Most of the chemical compounds were purchased from Tocris Bioscience (Bristol, UK). ZD 7288, isradipine, phorbol 12-myristate 13-acetate (PMA), and DNQX were purchased from Hello Bio (Bristol, UK); BAPTA, $\mathrm{Cd}^{++}$and $4 \alpha$-phorbol 12 -myristate 13 -acetate ( $4 \alpha$-PMA) were purchased from SigmaAldrich (St. Louis, MO, USA); TTX was purchased from Latoxan (Valence, France); NNC 55-0396 dihydrochloride (NNC 55-0396), DL-AP5, and anti-Nav1.9 antibody were purchased from Alomone Labs (Jerusalem, Israel); $A \beta_{1-42}$ was purchased from Abcam (Cambridge, UK); and normal IgG was purchased from Santa Cruz Biotechnology (Heidelberg, Germany).

Picrotoxin, DNQX, paxilline, isradipine, NPS 2143, PMA and $4 \alpha$-PMA were dissolved in DMSO. The final concentration of DMSO in the extracellular solutions containing these compounds was $0.01 \%$. In the experiments using compounds that were dissolved in DMSO, the control extracellular solution also contained DMSO at a concentration of $0.01 \%$. The remaining compounds were dissolved directly in the extracellular solution.

The experiments with PMA, $4 \alpha$-PMA and isradipine were performed in the dark.

Compounds were applied by dissolving them to the final concentration in the artificial cerebrospinal fluid (ACSF) and were added to the bath (VC-6 six-channel valve controller; Warner Instruments, LLC, Hamden, MA, USA) or to the pipette solution when indicated. One biologically active substance was tested only once on one pyramidal neuron.

\section{Statistics}

The data were analyzed using GraphPad Prism 7 (GraphPad Software, Inc., La Jolla, CA, USA). All results presented throughout the article and in the figures are shown as the means \pm SE. Unless otherwise indicated, paired Student's $t$-tests were used for statistical comparisons. Differences between groups were considered significant at $p<0.05$.

\section{RESULTS}

\section{Properties of Rebound Depolarization}

Membrane potential recordings were obtained from layer $\mathrm{V}$ mPFC pyramidal neurons in slices isolated from adult rats (58-62 days old). Glutamatergic and GABAergic transmission blockers were routinely added to the extracellular solution. The extracellular solution also contained TTX $(0.5 \mu \mathrm{M}$, except for the results presented in Figures $\mathbf{2 A - C}$ ). Therefore, the tested pyramidal neurons were synaptically isolated. The input resistance and cell membrane capacitance of tested pyramidal neurons were $110.7 \pm 4.6 \mathrm{M} \Omega(n=181)$ and $224.5 \pm 29.8 \mathrm{pF}$ $(n=192)$, respectively.

RD was typically evoked in the neurons as follows (exceptions are indicated in the text): the membrane potential was hyperpolarized using a negative current step of $-600 \mathrm{pA}$ that lasted $1000 \mathrm{~ms}$ (Figure 1Aa, prepulse). The hyperpolarizing prepulse was followed by current pulses lasting $200 \mathrm{~ms}$ each and applied in 20-pA increments from the $-100-\mathrm{pA}$ negative to +180 -pA positive current steps (with respect to the " 0 " current level, Figure 1Aa). These current pulses were followed by a negative current postpulse of $-200 \mathrm{pA}$ that lasted $1300 \mathrm{~ms}$ (Figure 1 Aa, postpulse). In Figure 1 Ab are shown membrane potential changes evoked by only two (from 15 shown in Figure 1Aa) current pulses: to $-20 \mathrm{pA}$ and to $0 \mathrm{pA}$, lasting $200 \mathrm{~ms}$ each. The $-20-\mathrm{pA}$ current pulse was subthreshold to evoke $\mathrm{RD}$ (Figure 1 $\mathbf{A b}^{*}$ ). Current pulsed to $0 \mathrm{pA}$ evoked RD that markedly outlasted the 200-ms current pulse duration (Figure 1Ab, RD). In the next Figures, usually two current pulses lasting $200 \mathrm{~ms}$ are shown: one just subthreshold and one threshold for RD, together with the subthreshold and threshold voltage responses (even though the voltage responses to all 200-ms current pulses shown in Figure 1Aa have been recorded). If $\mathrm{RD}$ could not be evoked, more than two 200-ms depolarizing current pulses together with voltage responses evoked by these current pulses were shown to demonstrate that high-threshold RDs were absent. 


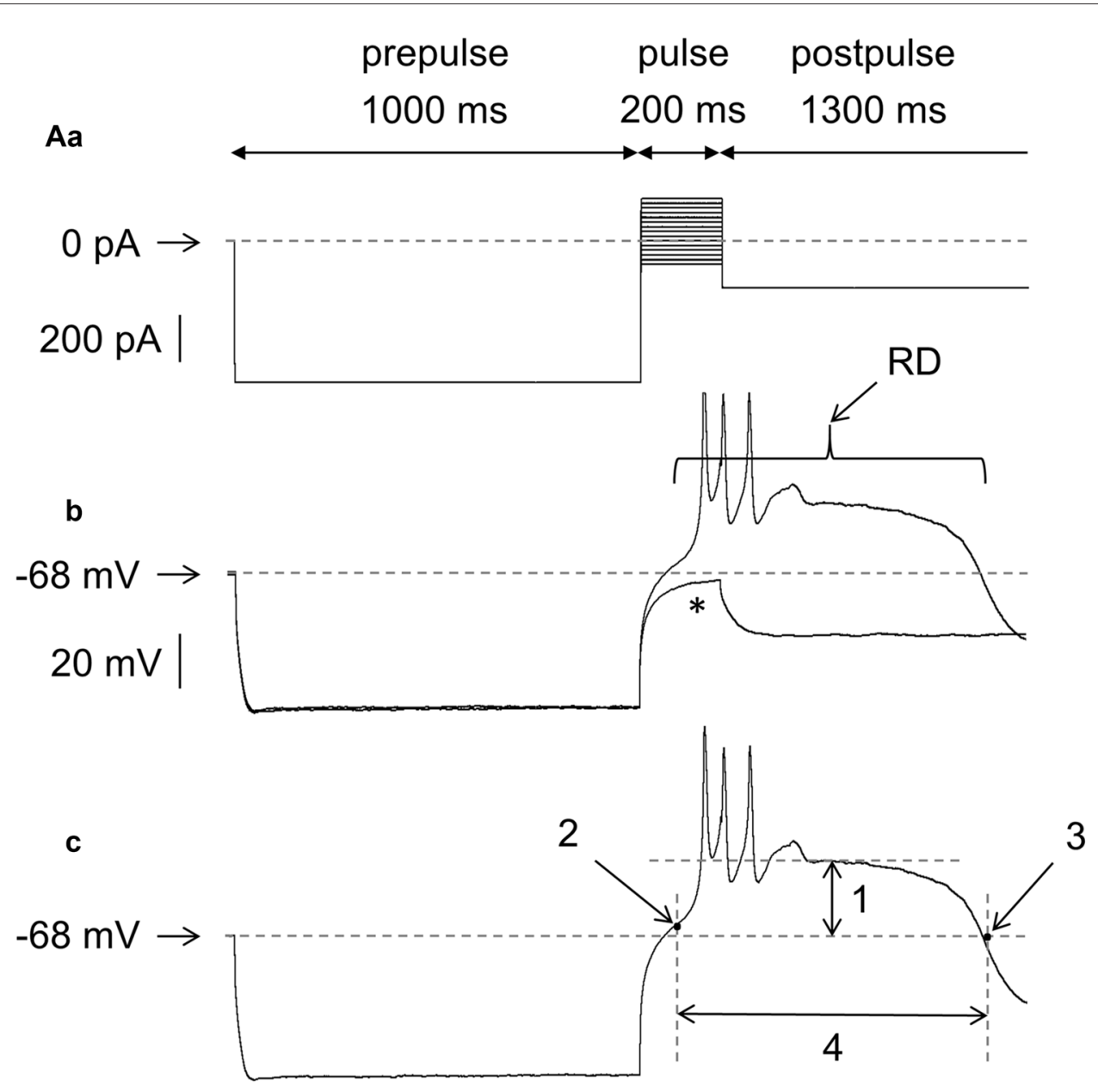

$\mathrm{Ba}$

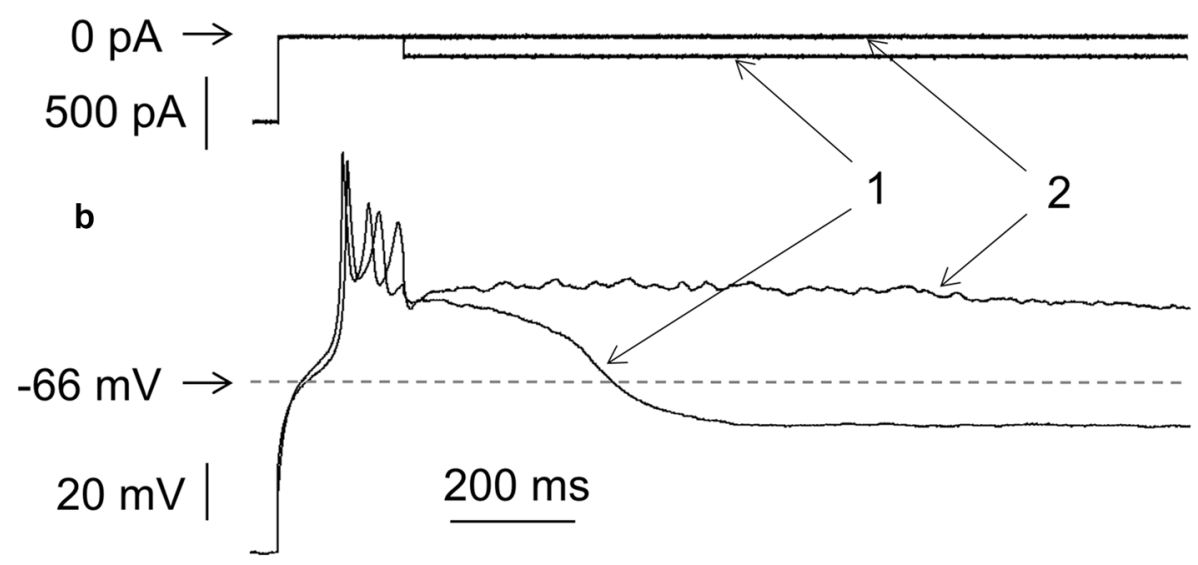

FIGURE 1 | Measurements of the amplitude and duration of rebound depolarization (RD) in medial prefrontal cortex (mPFC) pyramidal neurons. (Aa) Standard protocol applied to study RD. A 600-pA hyperpolarizing current prepulse lasting 1000 ms preceded 200-ms current pulses applied in 20-pA increments from $-100 \mathrm{pA}$ to $+180 \mathrm{pA}$. The $200-\mathrm{ms}$ current pulses were followed by a hyperpolarizing current postpulse at $-200 \mathrm{pA}$ that lasted $1300 \mathrm{~ms}$. (b) Membrane potential changes evoked by current pulses $-20 \mathrm{pA}\left(^{*}\right)$ and $0 \mathrm{pA}(\mathrm{RD})$ in the bath in the absence of $\mathrm{Ca}^{++}$. (c) An RD taken from (b). Double-headed arrow 1 indicates maximum depolarization above the resting membrane potential attained after repetitive tetrodotoxin (TTX)-resistant spikelets. Arrow 2 indicates the beginning of RD when the depolarization phase of the RD attained $10 \%$ of its maximum level. Arrow 3 indicates the RD end, which was defined as the time point at which the 


\section{FIGURE 1 | Continued}

$\mathrm{RD}$ repolarization phase intersected with the resting membrane potential level. Double-headed arrow 4 indicates the RD duration, defined as the time interval between the beginning and the end of the RD. (B) Voltage changes (b1, b2) evoked by a current pulse to $0 \mathrm{pA}$ (a) followed by postpulses to $-200 \mathrm{pA}$ (a1) and postpulse 0 pA (a2). The dotted horizontal line in panel (Aa) indicates

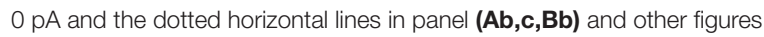
indicate the resting membrane potential level.

An additional hyperpolarizing current postpulse lasting $1300 \mathrm{~ms}$ (-200 pA, postpulse in Figure 1Aa) after 200-ms "pulses" was applied to shorten the RD duration. Without this additional postpulse, the $\mathrm{RD}$ duration was frequently longer than arbitrarily chosen by our analysis time (Figures 1Ba2,b2). Addition of a hyperpolarizing postpulse shortened the RD duration (Figures 1Ba1,b1).

The average 200-ms maximum current pulse that was subthreshold to evoke RD was $-9.3 \pm 3.8 \mathrm{pA}(n=192$, negative current pulse with respect to the " 0 " current level). The average minimum (threshold) current pulse that invariably evoked RD was $+10.7 \pm 3.8 \mathrm{pA}(n=192$, positive current with respect to the " 0 " current level). Therefore, the RD threshold corresponded to the current pulse amplitude in-between $-9 \mathrm{pA}$ and $+11 \mathrm{pA}-\mathrm{a}$ value close to the 0 -pA current level (a level that did not evoke a change in the resting membrane potential).

The amplitude of the $\mathrm{RD}$ was expressed as maximum depolarization above the resting membrane potential measured after the spikelets (after repetitive TTX-resistant fluctuating broad depolarizations seen at the beginning of the RD plateau, Figure 1Ac1). It was arbitrarily assumed that RD began when the depolarization phase of the RD attained $10 \%$ of its maximum level (Figure 1Ac2). The end of the RD was defined as the time point at which the RD repolarization phase intersected with the resting membrane potential level (Figure 1Ac3). The time interval between the beginning and the end of the $\mathrm{RD}$ was defined as the RD duration (Figure 1Ac4). RDs were evoked in $91 \%$ (192 out of 211 ) of the tested layer V pyramidal neurons. The resting membrane potential in these neurons was $-67.9 \pm 0.95 \mathrm{mV}(n=192)$, the amplitude of the $\mathrm{RD}$ was $30.6 \pm 1.2 \mathrm{mV}(n=192)$, and the $\mathrm{RD}$ duration was $564.3 \pm 39.6 \mathrm{~ms}(n=192)$. These measurements were obtained for RDs evoked by the threshold current pulse.

$\mathrm{RD}$ was never evoked in the presence of $\mathrm{Ca}^{++}$in the extracellular solution (tested at $\mathrm{Ca}^{++}$concentrations of $0.1 \mathrm{mM}$, $0.3 \mathrm{mM}$ and $1 \mathrm{mM}$, as shown in Figure $\mathbf{2 B}$ ), unless the $\mathrm{Ca}^{++}$(Figures 10Ac,d,Bc-e) or BK (Figures 7Ac,Ba) channel current was blocked, $\mathrm{Ca}^{++}$was chelated in the intracellular solution (Figures $\mathbf{8 B b}, \mathbf{C b}$ ), or protein kinase C (PKC) was activated (Figures 11Ac,e). RD was also evoked in the absence (Figure 2C) and presence of $0.5,1$ and $10 \mu \mathrm{M}$ of TTX in the extracellular solution (Figure 2D, shown in the presence of $0.5 \mu \mathrm{M}$ of TTX). Moreover, in the absence of TTX, irrespective of the presence (Figure $2 \mathrm{~B}$ ) or absence (Figure 2C) of $\mathrm{Ca}^{++}$in the bath, typical large-amplitude action potentials were evoked during depolarization. Small-amplitude, broad, repetitive depolarizations (spikelets) were evoked in the absence

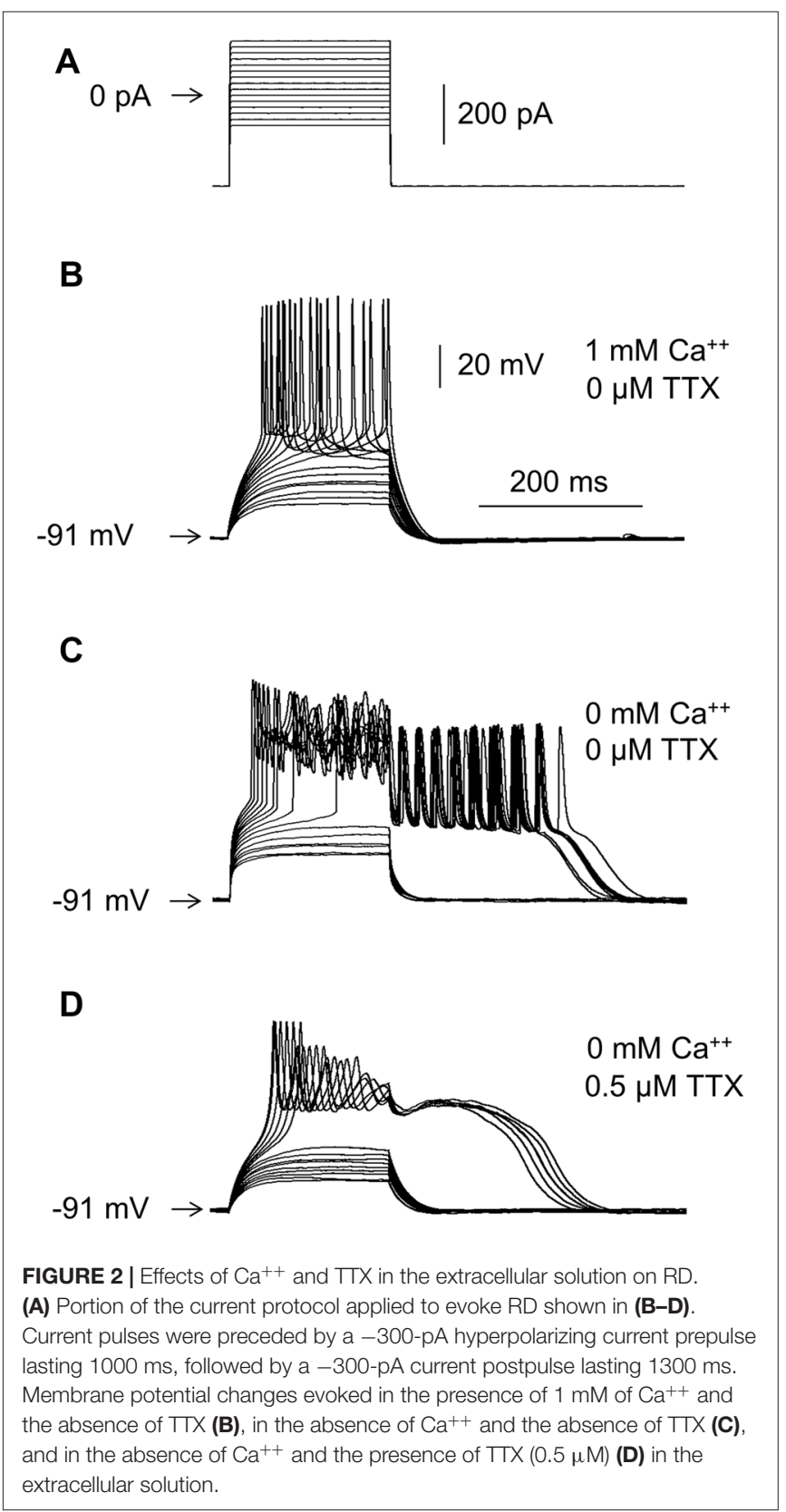

of $\mathrm{Ca}^{++}$, despite the presence of TTX in the bath (for example, Figure 2D).

The effects of the hyperpolarizing prepulse amplitude and duration were also examined during the absence of $\mathrm{Ca}^{++}$in the bath. To examine the effect of the prepulse level on $\mathrm{RD}$, we applied 1000-ms hyperpolarizing current prepulses from $-700 \mathrm{pA}$ to $-250 \mathrm{pA}$ in $50-\mathrm{pA}$ increments before the $200-\mathrm{ms}$ threshold current pulse that evoked RD (Figure 3Aa). The postpulse amplitude was $-300 \mathrm{pA}$. RD was abolished in an allor-none fashion at prepulse membrane potential levels above $-81.5 \pm 3.1 \mathrm{mV}(n=10$, Figure $3 \mathrm{Ab})$.

The hyperpolarizing prepulse duration on $\mathrm{RD}$ was tested as follows. At a prepulse amplitude of $-600 \mathrm{pA}$, the prepulse durations were as follows (in ms): 1000, 800, 600, 400, 200, 
$\mathrm{Aa}$
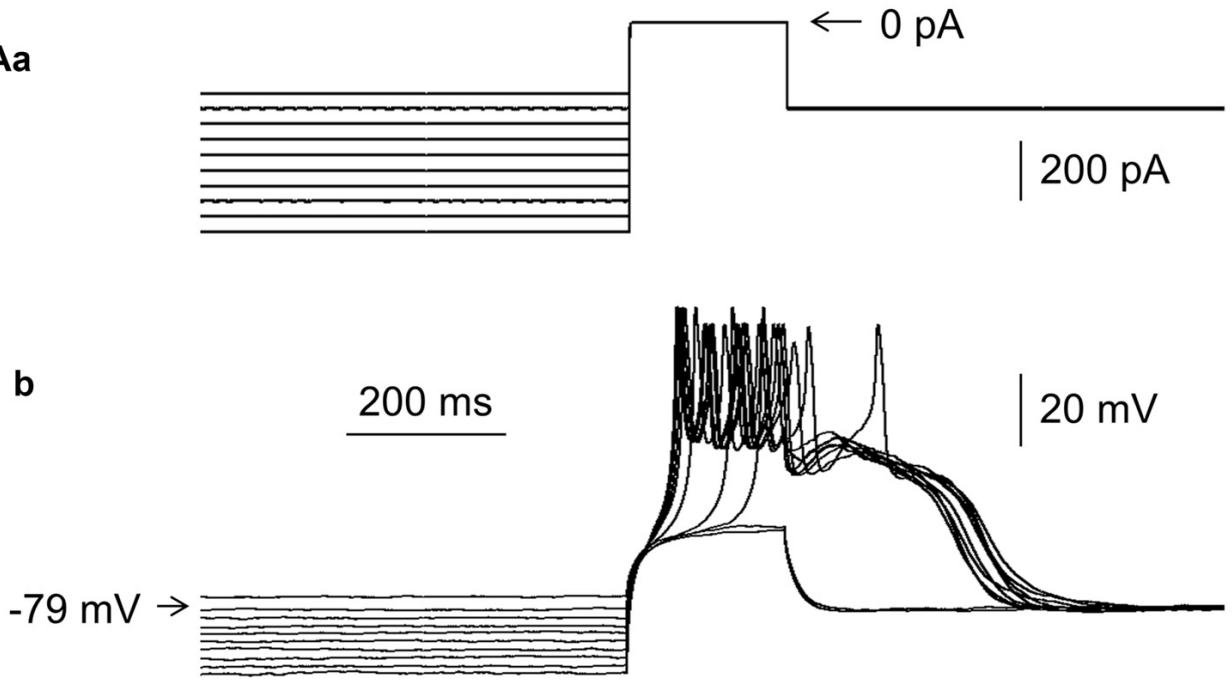

$\mathrm{Ba}$

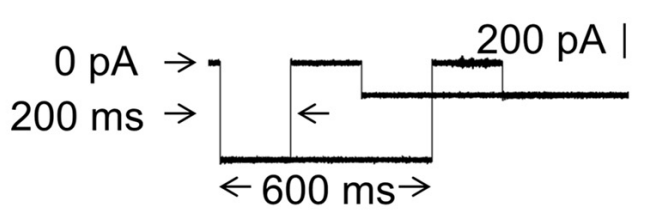

b

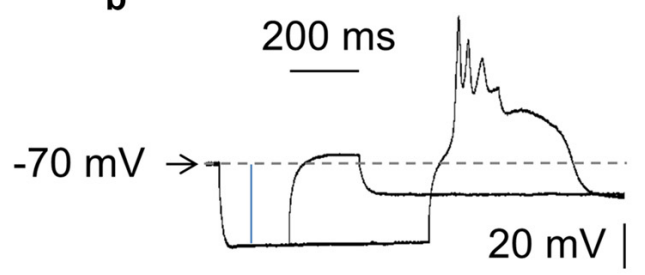

C

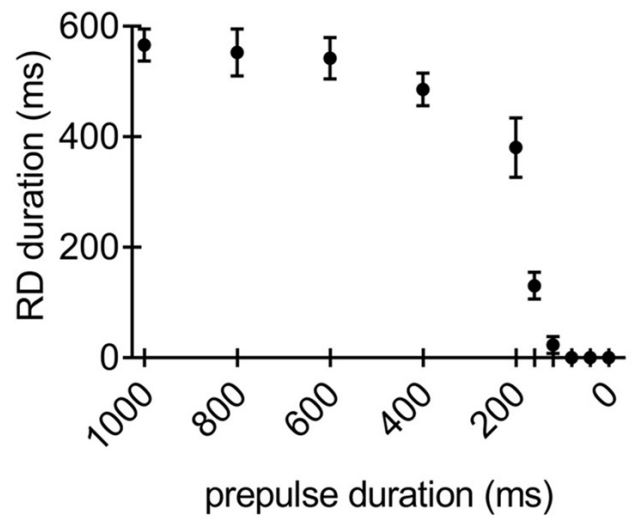

FIGURE 3 | Effects of the amplitude and duration of the prepulse on RD in the absence of $\mathrm{Ca}^{++}$in the extracellular solution. (Aa) Current protocol applied to study the effect of the prepulse amplitude on RD. Hyperpolarizing 1000-ms current prepulses from -700 pA to -250 pA were applied in 50-pA increments preceding the threshold current pulse to 0 pA, lasting 200 ms. Current pulses that evoked RD were followed by hyperpolarization to -300 pA, lasting 1300 ms. (b) RDs evoked by the current protocol shown in (a). RDs were evoked only at prepulse potentials more negative than $-79 \mathrm{mV}$. (Ba) Current protocol applied to study the effect of the prepulse duration on the RD duration. The prepulse amplitude was -600 pA. The prepulse duration was changed from 1000 to 0 ms. Only 2 prepulses with durations of 200 and 600 ms are shown. The 200-ms threshold current pulse that evoked RD was 0 pA. The postpulse amplitude was -200 pA and lasted 1300 ms. (b) RD was evoked at a prepulse duration of 600 ms, but not at a prepulse duration of 200 ms (protocol of current pulses is shown in a). (c) Relationship between prepulse duration (horizontal axis) and RD duration (vertical axis).

160, 120, 80, 40 and 0. Figures 3Ba,b shows RD evoked with a prepulse duration of $600 \mathrm{~ms}$ and the lack of $\mathrm{RD}$ with a prepulse duration of $200 \mathrm{~ms}$. With a prepulse duration shorter than $600 \mathrm{~ms}$, the RD duration also became gradually shorter, and $\mathrm{RD}$ was abolished with a prepulse duration shorter than $148.6 \pm 47.4 \mathrm{~ms}(n=7$, Figure 3Bc).

The above results indicated that the effector responsible for $\mathrm{RD}$ formation in $\mathrm{mPFC}$ pyramidal neurons had the following properties: (a) it was evoked in the absence of $\mathrm{Ca}^{++}$in the extracellular solution, (b) it was TTX-resistant, and (c) it was activated after the hyperpolarizing current step below $-81 \mathrm{mV}$ and lasting longer than $150 \mathrm{~ms}$. Its threshold after the hyperpolarizing step was close to the resting membrane potential level.

\section{Effector Responsible for RD}

Because RD was blocked in the presence of $\mathrm{Ca}^{++}$in the extracellular solution, the search for RD effectors was performed in the absence of $\mathrm{Ca}^{++}$in the bath.

The inward $\mathrm{Na}^{+}$current was responsible for $\mathrm{RD}$ because it was completely abolished when $125 \mathrm{mM}$ of $\mathrm{NaCl}$ was replaced with $125 \mathrm{mM}$ of choline- $\mathrm{Cl}$ in the extracellular solution and was recovered when the $\mathrm{Na}^{+}$gradient was restored $(n=7$, Figures 4A-D). 


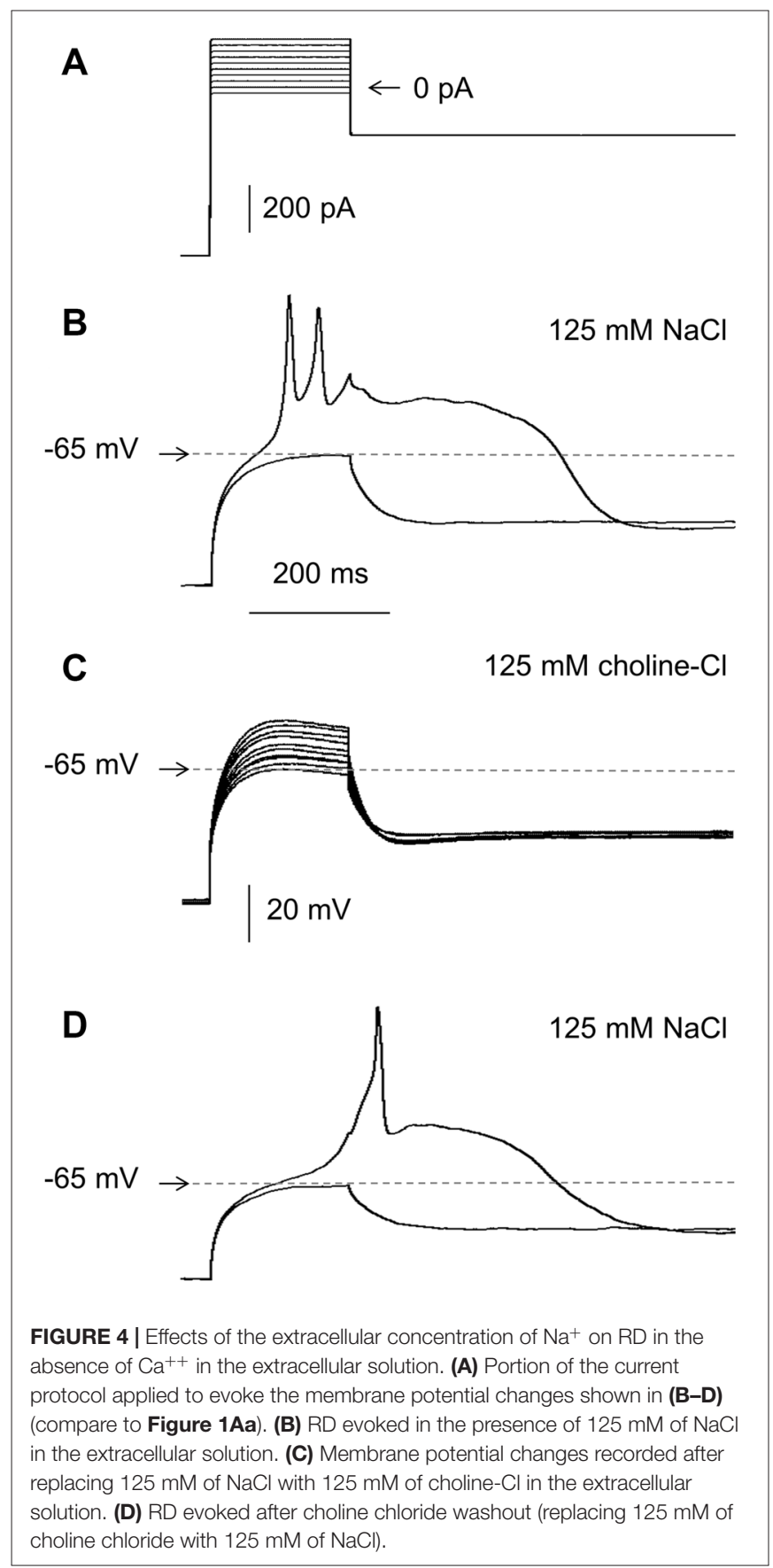

A number of membrane proteins may be responsible for $\mathrm{Na}^{+}$-dependent RD. HCN channels, which are permeable to $\mathrm{Na}^{+}$and $\mathrm{K}^{+}$and are inactivated in the steady-state at the resting membrane potential, are possible candidate channels, as suggested by others (Albertson et al., 2011). Layer V pyramidal neurons that project to subcortical structures have been shown to express this current, while those that project to the cortex do not (Dembrow et al., 2010; Lee et al., 2014). The presence of HCN currents is marked by a voltage sag at the beginning of the hyperpolarizing voltage step (Dembrow et al., 2010; Albertson et al., 2011; Lee et al., 2014). Indeed, in our study, bath application of a specific blocker of $\mathrm{HCN}$ channels (ZD 7288, $50 \mu \mathrm{M}, n=5$ ) abolished the voltage sag seen at the beginning of prepulse hyperpolarization (compare insets to Figures $\mathbf{5 A b}, \mathbf{c}$ ). Moreover, $\mathrm{RD}$ depolarization in the tested pyramidal neurons was found in cells with (Figure 5Ba and inset) and without (Figure $\mathbf{5 B b}$ and inset) a voltage sag. Furthermore, application of the HCN channel blockers ZD $7288(50 \mu \mathrm{M})$ or $\mathrm{Cs}^{+}(3 \mathrm{mM})$ to the extracellular solution did not affect the duration of RD. After a 15-min bath application of ZD 7288 (ZD 7288; $533.9 \pm 18.6 \mathrm{~ms}$, $n=9$, Figures 5Aa,c) or $\mathrm{Cs}^{+}(555.6 \pm 27.6 \mathrm{~ms}, n=7$, traces not shown), the duration of RD did not significantly differ from that of the $\mathrm{RD}$ duration measured immediately before blocker application (557.1 $\pm 29.1 \mathrm{~ms}, n=9, p>0.05$, Figure 5Ca and $565.2 \pm 22 \mathrm{~ms}, n=7, p>0.05$, Figure $5 \mathbf{C b}$, respectively). This finding indicated that $\mathrm{HCN}$ channels were not responsible for $\mathrm{RD}$ in $\mathrm{mPFC}$ pyramidal neurons.

We also considered whether NALCN $\left(\mathrm{Na}^{+}\right.$-leak channel) currents, which are inhibited in the presence of $\mathrm{Ca}^{++}$in the extracellular solution and are preferentially expressed in neurons (Cochet-Bissuel et al., 2014), might be responsible for RD. A 15-min bath application of NALCN blockers, including $\mathrm{Gd}^{+++}(100 \mu \mathrm{M})$ or verapamil $(1 \mathrm{mM}$; Boone et al., 2014), did not prevent $\mathrm{RD}$. The RD durations following $\mathrm{Gd}^{+++}(580.2 \pm 14.7 \mathrm{~ms}, n=7)$ or verapamil application $(540.6 \pm 33.5 \mathrm{~ms}, n=8)$ did not differ significantly from those measured before blocker application $(571.2 \pm 12.1 \mathrm{~ms}, n=7$, $p>0.05$ and $558.9 \pm 28.8 \mathrm{~ms}, n=8, p>0.05$, respectively). The effects of $\mathrm{Gd}^{+++}$and verapamil on $\mathrm{RD}$ are not shown in the figures.

Persistent (i.e., non-inactivating over time) $\mathrm{Na}^{+}$currents have also been proposed to be responsible for RD (Sangrey and Jaeger, 2010). It was recently suggested that low-threshold and TTX-resistant Nav1.9 $\mathrm{Na}^{+}$channel currents are present in layer V mPFC pyramidal neurons (Kurowski et al., 2015; Gawlak et al., 2017). To test whether these channels are responsible for RD, an antibody against Nav1.9 channels $(4 \mu \mathrm{g} / \mathrm{ml})$ was applied through the recording pipette to the tested pyramidal neurons. The RD durations were $462.5 \pm 12.6 \mathrm{~ms}(n=3$; Figures $6 \mathbf{A b}, \mathrm{Ca}$, anti-Nav1.9, $15 \mathrm{~min}$ ) and $54.8 \pm 34.8 \mathrm{~ms}$ $(n=6$; Figures $6 \mathbf{A a}, \mathbf{c}, \mathbf{C b}$, anti-Nav1.9, $60 \mathrm{~min})$ when measured at 15 and $60 \mathrm{~min}$, respectively, after application of the antibody. In four out of six cases, after $60 \mathrm{~min}$ of intracellular presence of anti-Nav1.9 antibody, the RD was completely abolished (Figures 6Aa,c,Cb). As a control, normal $\operatorname{IgG}(4 \mu \mathrm{g} / \mathrm{ml})$ was applied to the cells. The RD durations measured at 15 and $60 \mathrm{~min}$ after the onset of cell "dialysis" with IgG were $517.8 \pm 27.3 \mathrm{~ms}$ $(n=3$; Figures $6 \mathrm{Ba}, \mathbf{b}, \mathrm{Ca}, \mathrm{IgG}, 15 \mathrm{~min})$ and $585.3 \pm 115.3 \mathrm{~ms}$ ( $n=6$; Figures $\mathbf{6 B a}, \mathbf{c}, \mathbf{C b}$, IgG, $60 \mathrm{~min}$ ). The $\mathrm{RD}$ durations measured during the intracellular application of $\operatorname{IgG}$ were not significantly different (unpaired Student's $t$-test, $p>0.05$ ) from those measured in the absence of any tested biologically active compounds in the extra- and intracellular solutions $(564.3 \pm 39.6 \mathrm{~ms}, n=192)$. The duration of RD was significantly shorter in the presence of the anti-Nav1.9 antibody than that in the presence of $\operatorname{IgG}(p=0.0001$, unpaired Student's $t$-test $)$ when measured at $60 \mathrm{~min}$ after antibody application to the cells (Figure 6Cb). 
$\mathrm{Aa}$

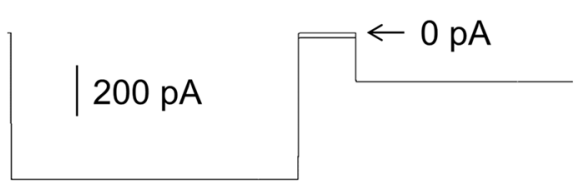

b

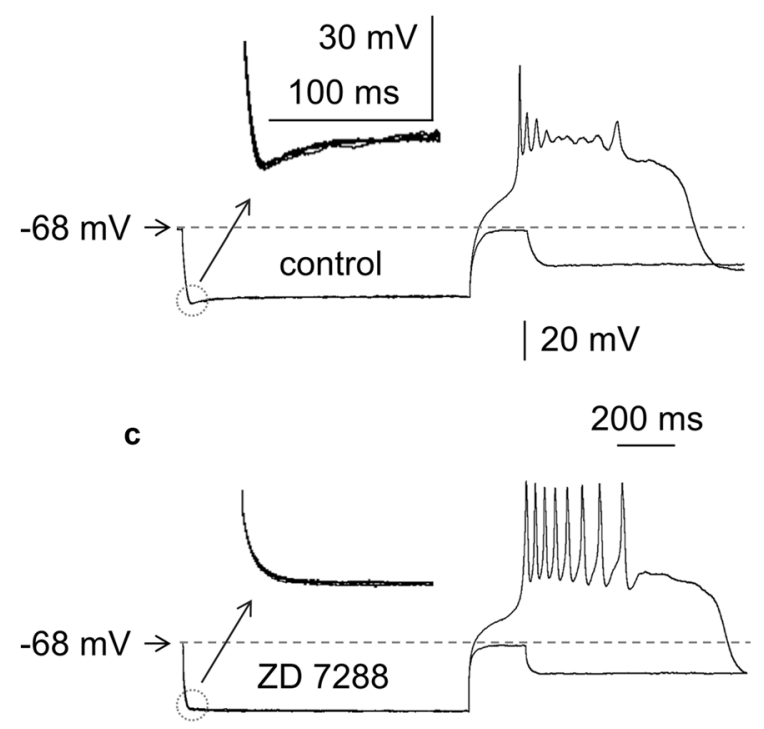

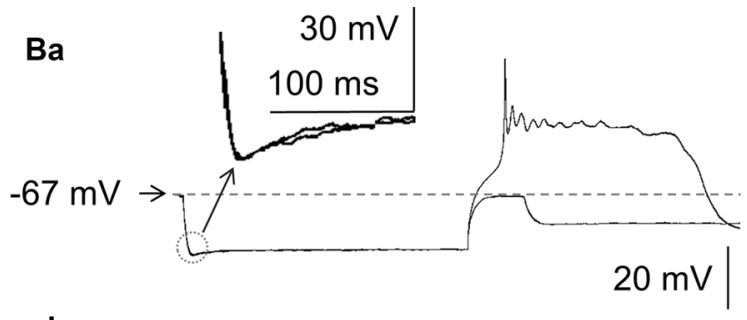

b

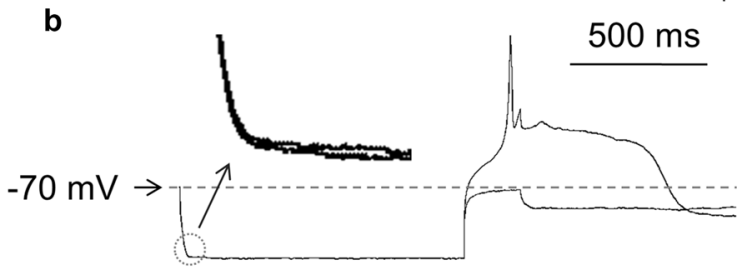

C

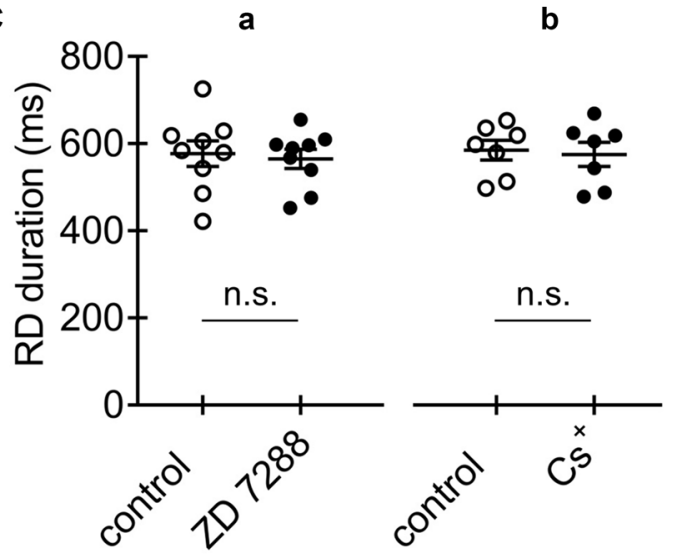

FIGURE 5 | Effects of HCN channel blockers on RD in the absence of $\mathrm{Ca}^{++}$in the extracellular solution. (Aa) Current protocol applied to evoke the membrane potential changes shown in (b,c) (compare to Figure 1Aa). RD evoked before (b) and during (c) bath application of ZD 7288 (50 $\mu$ M). Insets to (b,c) show amplified voltage responses to the beginning of the rectangular hyperpolarizing current steps. Voltage sag was present before (inset to $\mathbf{b}$ ) and was absent during bath application of ZD 7288 (50 $\mu \mathrm{M}$, inset to c). (B) Examples of RDs evoked in two pyramidal neurons, in which voltage sag was present (a) and absent (b). Insets show amplified voltage responses to the beginning of the rectangular hyperpolarizing current steps. The current protocol applied to evoke RD is shown in Figure 1Aa. (C) Duration of RD before (control) and after 15-min bath application of either ZD 7288 (a, ZD 7288, $50 \mu \mathrm{M}$ ) or $\mathrm{Cs}^{+}$(b, Cs ${ }^{+}$, 3 mM); n.s., non-significant.

Others (Coste et al., 2004) have indicated that in the presence of $\mathrm{F}^{-}$in the pipette solution, the threshold of the inward Nav1.9 currents shift toward hyperpolarization. Therefore, we measured the current threshold of $\mathrm{RD}$ when only $\mathrm{Cl}^{-}$anions were present and when $20 \mathrm{mM}$ of $\mathrm{KCl}$ was replaced with $20 \mathrm{mM}$ of $\mathrm{KF}$ in the pipette solution. The threshold was expressed as minimum amplitude of the 200-ms current pulse applied after the hyperpolarizing prepulse (Figure 1Aa) that evoked RD. The RD thresholds were $+8.0 \pm 10.2 \mathrm{pA}(n=5)$, $+4.0 \pm 16.0 \mathrm{pA}(n=5)$, and $+4.0 \pm 14.7 \mathrm{pA}(n=5)$ measured at 15, 25 and $35 \mathrm{~min}$ after the onset of cell "dialysis" with standard $\mathrm{Cl}^{-}$-containing solution (Figure 6D, control). The RD thresholds were $-107.5 \pm 44.1 \mathrm{pA}(n=8),-248.0 \pm 45.0 \mathrm{pA}$ $(n=5)$, and $-286.7 \pm 43.7 \mathrm{pA}(n=3)$ at 15,25 , and $35 \mathrm{~min}$ after the onset of cell "dialysis" with $\mathrm{F}^{-}$(Figure $6 \mathrm{D}, \mathrm{F}^{-}$). The $\mathrm{RD}$ threshold was significantly decreased after $25 \mathrm{~min}$ $(p=0.0007$, unpaired Student's $t$-test $)$ and $35 \mathrm{~min}(p=0.0002$, unpaired Student's $t$-test) of cell "dialysis" with $\mathrm{F}^{-}$compared with the $\mathrm{RD}$ thresholds measured at the same time points in the presence of only $\mathrm{Cl}^{-}$anions in the intracellular solution (Figure 6D).

These results suggest that the low-threshold and TTX-resistant inward $\mathrm{Na}^{+}$current, presumably through Nav1.9 channels, is responsible for $\mathrm{RD}$ in pyramidal neurons.

\section{Effector Responsible for Restraining RD}

RDs were not evoked in the presence of $\mathrm{Ca}^{++}$in the extracellular solution. It has been thoroughly documented that the removal of $\mathrm{Ca}^{++}$from the extracellular solution decreases the baseline $\mathrm{Ca}^{++}$concentration in the cytoplasm in both neurons (Magee et al., 1996; Pinilla et al., 2005; Cheek and Thorn, 2006; Nichols et al., 2007) and nonneuronal cells (Mignen et al., 2017). Decreasing the $\mathrm{Ca}^{++}$concentrations in the cytoplasm leads to a markedly increased voltage threshold of BK channels (large conductance $\mathrm{Ca}^{++}$-activated $\mathrm{K}^{+}$channels; Berkefeld and Fakler, 2013). We assumed that the depletion of $\mathrm{Ca}^{++}$in the extracellular solution lowers the $\mathrm{Ca}^{++}$levels in the cytoplasm and inhibits the outward $\mathrm{K}^{+}$current through $\mathrm{BK}$ channels, 


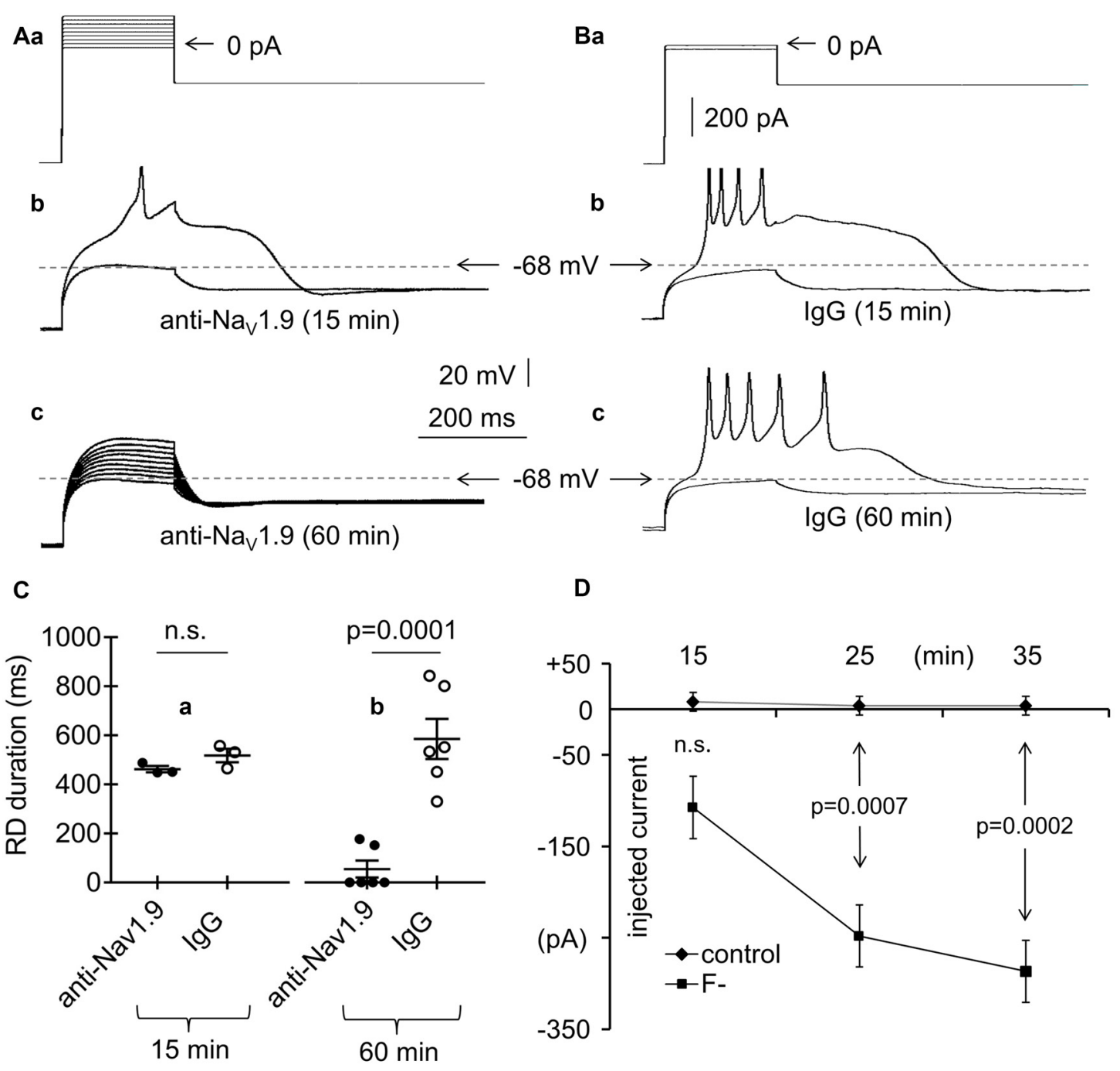

FIGURE 6 | Effects of an anti-Nav1.9 channel antibody, lgG and $\mathrm{F}^{-}$on $\mathrm{RD}$ in the absence of $\mathrm{Ca}^{++}$in the extracellular solution. (Aa) Current protocol applied to evoke RD (compare Figure 1Aa). (b) Voltage responses to subthreshold -20-pA and threshold 0-pA current pulses lasting 200 ms are shown. Voltage responses were recorded after the 15-min pipette presence of anti-Nav1.9 channel antibody (4 $\mathrm{gg} / \mathrm{ml}$, anti-Nav1.9, $15 \mathrm{~min})$. (c) Voltage responses to currents steps shown in (a) after loading the cell for $60 \mathrm{~min}$ with anti-Nav1.9 channel antibody $(4 \mu \mathrm{g} / \mathrm{ml}$, anti-Nav1.9, $60 \mathrm{~min})$. In (b,c) are shown recordings obtained from the same neuron. (B) Current protocol applied to evoke RD shown in (b,c). (a) Voltage response to -20 pA subthreshold and 0 pA threshold current pulses lasting $200 \mathrm{~ms}$ recorded

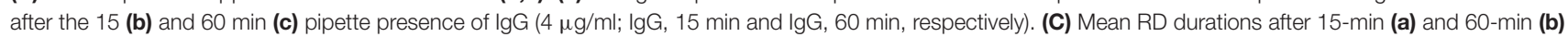
intracellular applications of anti-Nav1.9 antibody (anti-Nav1.9) or lgG (IgG). (D) RD current thresholds recorded during 15, 25 and 35 min in the presence of either only $\mathrm{Cl}^{-}$(control) or $\mathrm{Cl}^{-}$and $\mathrm{F}^{-}\left(\mathrm{F}^{-}\right)$in the pipette solution; n.s., non-significant.

allowing for the emergence of $\mathrm{Na}^{+}$-dependent RD. To test this hypothesis, a standard current-clamp protocol was applied (Figure 7Aa). As expected, RD was not evoked in the presence of $\mathrm{Ca}^{++}(1 \mathrm{mM})$ in the extracellular solution (Figures $7 \mathrm{Ab}, \mathbf{B a}$, $\mathrm{Ca}^{++}$). When a BK channel blocker (paxilline, $10 \mu \mathrm{M}$; Książek et al., 2013) was applied to the bath, a typical RD was elicited, despite the presence of $\mathrm{Ca}^{++}(1 \mathrm{mM})$ in the extracellular solution (Figures $7 \mathrm{Ac}, \mathrm{Ba}, \mathrm{Ca}^{++}+$paxilline). $\mathrm{RD}$ was eliminated after paxilline washout (Figure 7Ad). The duration of $\mathrm{RD}$ in the presence of $\mathrm{Ca}^{++}$and paxilline was $516.6 \pm 25.1 \mathrm{~ms}$ $(n=10)$ and did not differ from the RD duration measured in the absence of $\mathrm{Ca}^{++}$or any other tested compound in the extracellular solution $(564.3 \pm 39.6 \mathrm{~ms}, n=192, p>0.05$, unpaired Student's $t$-test). The resting membrane potentials before $(-67.5 \pm 1.2 \mathrm{mV})$ and after $(-67.9 \pm 0.8 \mathrm{mV})$ 15-min bath application of paxilline $(10 \mu \mathrm{M})$ were not significantly different $(n=10, p>0.05)$.

$\mathrm{Ca}^{++}$-dependent SK-type $\mathrm{K}^{+}$channels are also expressed in mPFC pyramidal neurons (Faber, 2010). Therefore, we also examined the putative involvement of SK currents in RD. When $\mathrm{Ca}^{++}(1 \mathrm{mM})$ was present in the extracellular solution, $\mathrm{RD}$ could not be evoked, irrespective of the absence (Figure $7 \mathbf{B b}, \mathrm{Ca}^{++}$, $n=7$ ) or 15 -min presence of a selective SK channel blocker (apamin, $50 \mathrm{nM}$; Figure $7 \mathbf{B b}, \mathrm{Ca}^{++}+$apamin, $n=7$ ) in the bath. 

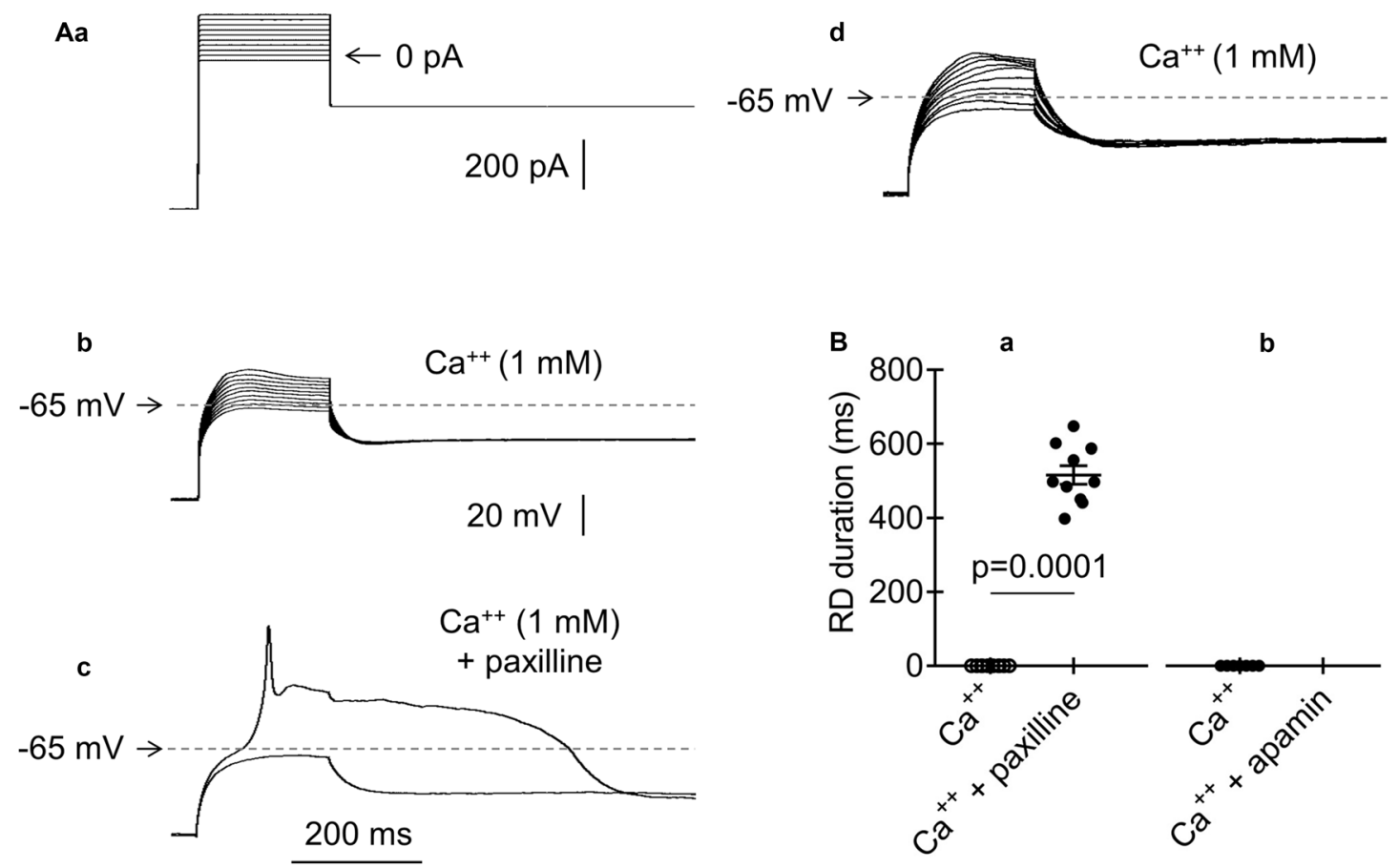

FIGURE 7 | Effects of BK and SK channel blockers on RD in the presence of $\mathrm{Ca}^{++}(1 \mathrm{mM})$ in the extracellular solution. (Aa) The current protocol (compare to Figure 1Aa) applied to evoke membrane potential changes shown in (b-d). Membrane potential changes evoked before (b), after a 15-min application of paxilline $(10 \mu \mathrm{M})$ (c), and after paxilline washout (d). (c) Membrane potential changes to 200 -ms pulses to -40 pA (subthreshold step) and to -20 pA (threshold step). (B) Absence of $\mathrm{RD}$ in the presence of only $\mathrm{Ca}^{++}(1 \mathrm{mM})$ in the extracellular solution $\left(\mathbf{B a}, \mathbf{b}, \mathrm{Ca}^{++}\right)$. Duration of $\mathrm{RD}$ and the presence of $\mathrm{Ca}++(1 \mathrm{mM})$ together with paxilline $\left(\mathbf{a}, 10 \mu \mathrm{M}, \mathrm{Ca}^{++}+\right.$paxilline). Absence of $\mathrm{RD}$ in the bath presence of $\mathrm{Ca}^{++}(1 \mathrm{mM})$ together with apamin $(\mathbf{b}, 50 \mathrm{nM}, \mathrm{Ca}+++$ apamin).

This finding suggests that SK channels are not involved in the modulation of RD.

Chelators of $\mathrm{Ca}^{++}$(EGTA, $10 \mathrm{mM}$ or BAPTA, $100 \mu \mathrm{M}$ ) were applied to the pipette solution to further evaluate the involvement of $\mathrm{BK}$ channels in the abolishment of $\mathrm{RD}$. RD was evoked using a standard protocol (Figure 8Aa, compare Figure 1Aa). Immediately after gaining access to the cytoplasm with the recording pipette containing EGTA, typical RD was evoked in the absence of $\mathrm{Ca}^{++}$in the extracellular solution (Figures 8Ab,Ca, control; $535.7 \pm 24.2 \mathrm{~ms}, n=8$ ). In the same neurons, RD was not evoked 60 min after cell "dialysis" with EGTA in the presence of $\mathrm{Ca}^{++}(1 \mathrm{mM})$ in the bath (Figures 8Ac, Ca, Ca ${ }^{++}+$EGTA). At the beginning of cell "dialysis" with BAPTA in the absence of $\mathrm{Ca}^{++}$in the bath, the $\mathrm{RD}$ duration was $541.8 \pm 31.7 \mathrm{~ms}$ (Figures $\mathbf{8 B a}, \mathbf{C b}$, control, $n=9$ ). At $60 \mathrm{~min}$ after cell "dialysis" with BAPTA, despite the extracellular presence of $\mathrm{Ca}^{++}(1 \mathrm{mM}), \mathrm{RD}$ was evoked. Under these conditions, the RD duration was $505.6 \pm 15.5 \mathrm{~ms}$ (Figures 8Bb,Cb, Ca ${ }^{++}+$BAPTA, $n=9$ ) and was not different from the $\mathrm{RD}$ duration measured at the beginning of cell "dialysis" with BAPTA (Figure 8Cb, $p>0.05$ ). The obtained results indicated that intracellular $\mathrm{Ca}^{++}$chelation with BAPTA abolished the inhibitory effect of BK channel activation on RD. The superior effectiveness of BAPTA over EGTA buffer in the elimination of the effect of $\mathrm{Ca}^{++}$on $\mathrm{BK}$ channels has been well documented (Fakler and Adelman, 2008).
Cortical neurons also express $\mathrm{Na}^{+}$-dependent $\mathrm{K}^{+}$currents (Slick and Slack channels, $\mathrm{K}_{\mathrm{Na}}$; Uchino et al., 2003; Bhattacharjee et al., 2005). $\mathrm{Na}^{+}$entering the cell during $\mathrm{RD}$ may activate $\mathrm{K}_{\mathrm{Na}}$ currents and shorten the RD duration (Krey et al., 2010). $\mathrm{Ba}^{++}$blocks $\mathrm{K}_{\mathrm{Na}}$ channels (Bhattacharjee et al., 2005), while $\mathrm{Li}^{+}$, to which $\mathrm{Na}^{+}$channels are permeable, has been shown to barely activate $\mathrm{K}_{\mathrm{Na}}$ (Kaczmarek, 2013). Tests with $\mathrm{Ba}^{++}$and $\mathrm{Li}^{+}$were performed in the absence of $\mathrm{Ca}^{++}$in the extracellular solution. We found that the duration of RD was $537.0 \pm 22.6 \mathrm{~ms}$ (Figure 9Aa, control, $n=8$ ) before and $520.8 \pm 28.4 \mathrm{~ms}$ after 15-min bath application of $\mathrm{Ba}^{++}\left(200 \mu \mathrm{M}\right.$; Figure 9Aa, $\mathrm{Ba}^{++}$, $n=8 ; p>0.05)$. We examined whether replacement of $125 \mathrm{mM}$ of $\mathrm{NaCl}$ with $125 \mathrm{mM}$ of $\mathrm{LiCl}$ in the extracellular solution could influence the duration of RD. The durations of RD before $(565.7 \pm 15.5 \mathrm{~ms}$; Figure 9Ab, control, $n=7)$ and after the replacement of $\mathrm{Na}^{+}$with $\mathrm{Li}^{+}\left(547.7 \pm 26.6 \mathrm{~ms}\right.$; Figure $9 \mathrm{Ab}, \mathrm{Li}^{+}$, $n=7)$ were not significantly different $(p>0.05)$, suggesting that $\mathrm{Na}^{+}$-dependent $\mathrm{K}^{+}$channels were not involved in shortening the $\mathrm{RD}$ duration.

Another consideration is that activation of $\mathrm{Na}^{+} / \mathrm{K}^{+}$-ATPase may participate in shortening the RD duration (Krey et al., 2010; Forrest et al., 2012). $\mathrm{Na}^{+} / \mathrm{K}^{+}$-ATPase may be activated by $\mathrm{Na}^{+}$ entering the cell during RD. Experiments were performed in the absence of $\mathrm{Ca}^{++}$in the extracellular solution. A 15-min application of the $\mathrm{Na}^{+} / \mathrm{K}^{+}$-ATPase blocker ouabain $(100 \mu \mathrm{M})$ did not prolong the RD evoked in pyramidal neurons. The 
Aa

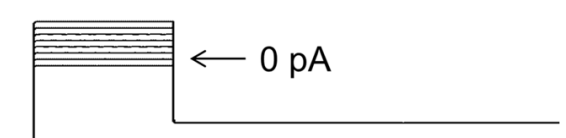

200 pA

b

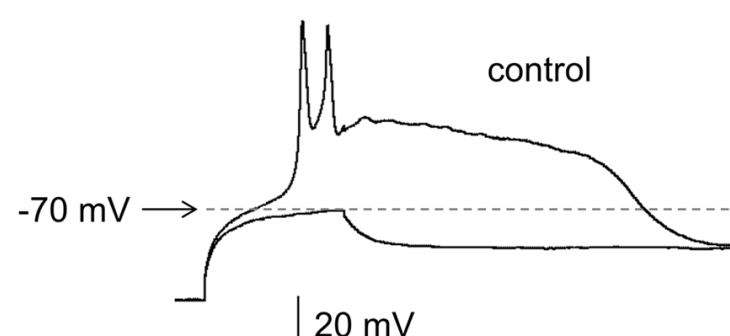

$20 \mathrm{mV}$

c

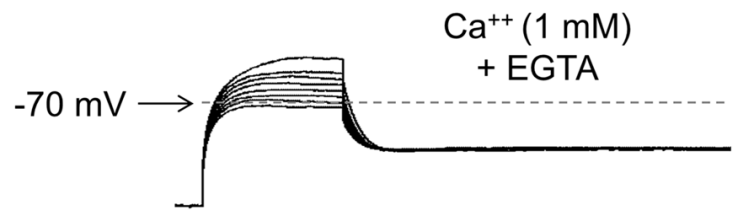

Ba

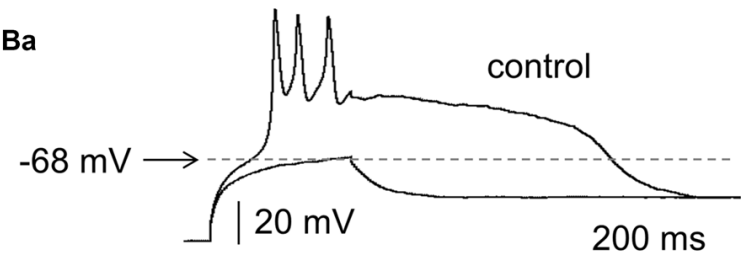

b

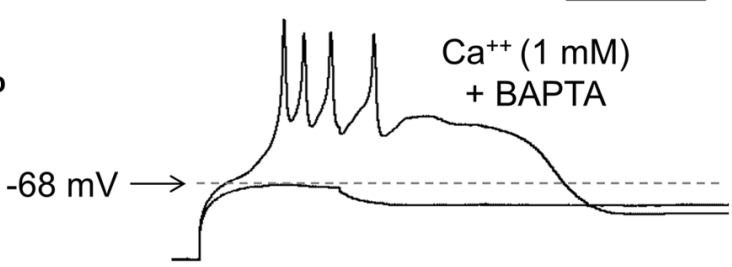

C

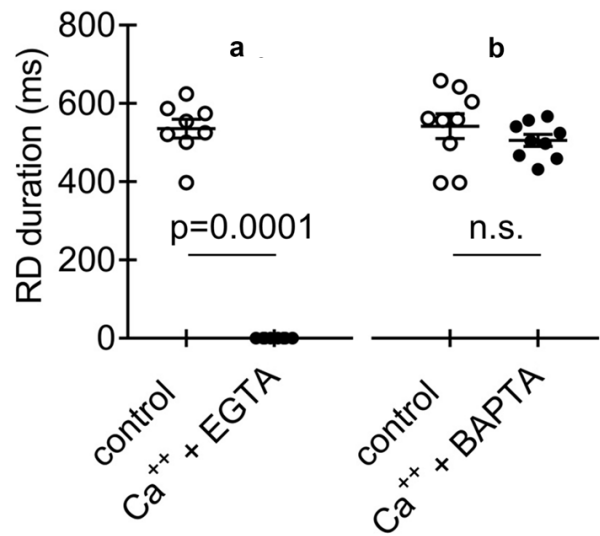

FIGURE $\mathbf{8}$ | Effects of intracellular application of EGTA or BAPTA on RD. (Aa) Current protocol applied to evoke RDs shown in (Ab,c,Ba,b) (compare Figure 1Aa). (b) Voltage responses evoked by pulse amplitudes of $0 \mathrm{pA}$ (subthreshold) and +20 pA (threshold required to evoke RD). RD was evoked at the beginning of cell "dialysis" with EGTA $(10 \mathrm{mM})$ in the absence of $\mathrm{Ca}^{++}$in the extracellular solution (control). (c) RD was not evoked after 60 min of cell "dialysis" with EGTA in the bath presence of $\mathrm{Ca}^{++}\left(1 \mathrm{mM}, \mathrm{Ca}^{++}+\mathrm{EGTA}\right)(\mathbf{b}$ and $\mathbf{c}$ show the results obtained from the same neuron). (Ba) RD was evoked at the beginning of cell "dialysis" with BAPTA $(100 \mu \mathrm{M})$ in the absence of $\mathrm{Ca}^{++}$(control). (b) RD was evoked in the same neuron after 60 min of cell "dialysis" with BAPTA despite the presence of Ca ${ }^{++}$in the extracellular solution ( $1 \mathrm{mM}, \mathrm{Ca}^{++}+$BAPTA). Voltage responses were evoked by $200-\mathrm{ms}$ current steps to $0 \mathrm{pA}$ (subthreshold) and to +20 pA (threshold current step required to evoke RD). (C) The RD duration measured at the beginning of cell "dialysis" with EGTA (a, control) or BAPTA (b, control) in the absence of Ca++ in the extracellular solution. RD could not be evoked after 60 min of cell dialysis with EGTA (a, Ca ${ }^{++}+$EGTA) in the bath presence of $\mathrm{Ca}^{++}(1 \mathrm{mM})$. RD was evoked after 60 min of cell dialysis with BAPTA (b, Ca ${ }^{++}+$BAPTA), despite the presence of $\mathrm{Ca}^{++}(1 \mathrm{mM})$ in the extracellular solution; n.s., non-significant.

durations of $\mathrm{RD}$ in the absence and presence of ouabain in the extracellular solution were $530.7 \pm 19.9$ ms (Figure 9B, control, $n=8$ ) and $542.4 \pm 20.5 \mathrm{~ms}$ (Figure 9B, ouabain, $n=8$ ), respectively; these values were not significantly different $(p>0.05)$.

The above results suggest that RD is not detected in the bath in the presence of $\mathrm{Ca}^{++}$, most likely because $\mathrm{Ca}^{++}$enters the cell cytoplasm and activates the outward $\mathrm{K}^{+}$current through BK channels. The outward $\mathrm{K}^{+}$current counterbalances the inward $\mathrm{Na}^{+}$current and extinguishes RD.

\section{Route of $\mathrm{Ca}^{++}$Entry Into the Cell Following the Hyperpolarization Current Step}

The above results indicate that low-threshold $\mathrm{Na}^{+}$and $\mathrm{Ca}^{++}$channels are simultaneously activated when the membrane potential returns to its resting level after the hyperpolarization step.
To identify the route through which $\mathrm{Ca}^{++}$passes from the extra- to the intracellular solution after the hyperpolarizing current step, we applied the nonselective $\mathrm{Ca}^{++}$channel blocker $\mathrm{Cd}^{++}(50 \mu \mathrm{M})$ to the bath. The standard current-clamp protocol (compare Figure 10Aa) did not evoke $\mathrm{RD}$ in the presence of $\mathrm{Ca}^{++}(1 \mathrm{mM})$ and the absence of $\mathrm{Cd}^{++}$(Figures 10Ab,d, $\left.\mathrm{Ca}^{++}, n=10\right)$ in the bath. When $\mathrm{Cd}^{++}$was added to the extracellular solution, RD depolarization was evoked, despite the extracellular presence of $\mathrm{Ca}^{++}(1 \mathrm{mM}$, Figure 10Ac). The RD duration under this condition was $515.9 \pm 18.0 \mathrm{~ms}$ (Figure 10Ad, $\mathrm{Ca}^{++}+\mathrm{Cd}^{++}, n=10$ ) and did not differ from the $\mathrm{RD}$ duration recorded in the absence of $\mathrm{Ca}^{++}$in the extracellular solution ( $p>0.05$, unpaired Student's $t$-test, $564.3 \pm 39.6 \mathrm{~ms}$, $n=192)$.

Low-threshold T-type $\mathrm{Ca}^{++}$channels are de-inactivated after membrane hyperpolarization (Molineux et al., 2006; Zamponi et al., 2010). To identify T-type channels as a potential route 


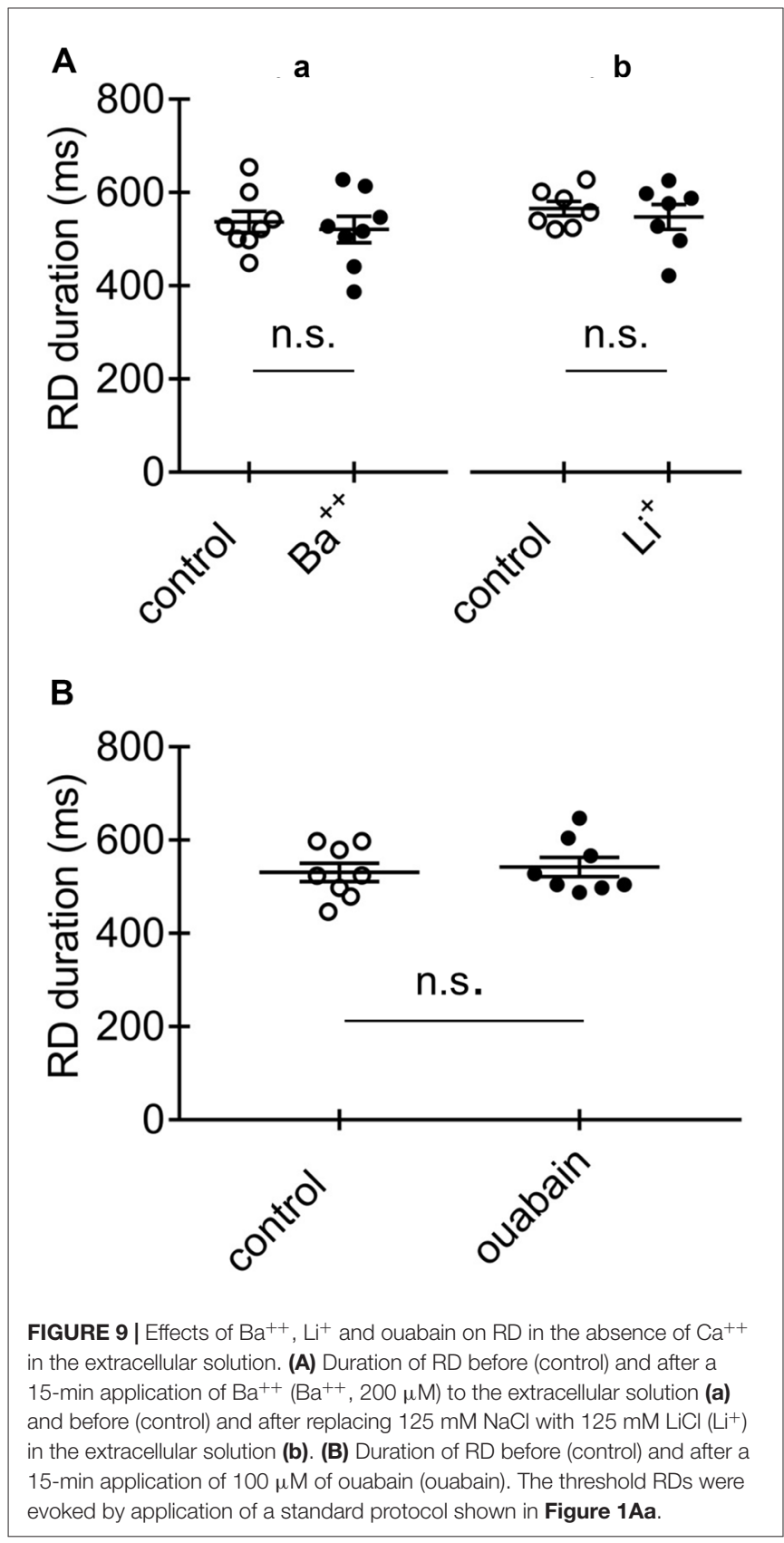

of $\mathrm{Ca}^{++}$entry into the cytoplasm after the hyperpolarization current step, we applied the highly selective T-type channel blocker NNC 55-0396 (50 $\mu \mathrm{M})$ to the bath. As expected, RD was not evoked in the presence of $0.1 \mathrm{mM}$ of $\mathrm{Ca}^{++}$and the absence of the T-type channel blocker (Figures $\mathbf{1 0 B a}, \mathbf{b}, \mathbf{d}, \mathrm{Ca}^{++}, n=9$ ).

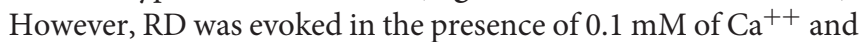
NNC 55-0396 (516.7 \pm 27.0 ms; Figures 10Bc,d, $\mathrm{Ca}^{++}+\mathrm{NNC}$ $55-0396, n=9)$. At higher $\mathrm{Ca}^{++}$concentrations $(0.3 \mathrm{mM}$ and above), RD could not be evoked, despite the presence of NNC 55-0396 in the bath.

A low-threshold voltage-dependent $\mathrm{L}$-type $\mathrm{Ca}^{++}$channel current has been described (Magee et al., 1996; Lipscombe et al., 2004; Navedo et al., 2005; Kolaj et al., 2016). Isradipine is an effective blocker of this current (Campbell et al., 1997; Anekonda et al., 2011). In our study, bath application of isradipine $(10 \mu \mathrm{M})$ permitted RD $(537.6 \pm 29.0 \mathrm{~ms}, n=8)$ in the presence of $\mathrm{Ca}^{++}$ in the bath at a concentration of $0.1 \mathrm{mM}$ (Figure 10Be, $\mathrm{Ca}^{++}+$ isradipine). At higher $\mathrm{Ca}^{++}$concentrations ( $0.3 \mathrm{mM}$ and above), $\mathrm{RD}$ could not be evoked, despite the presence of this L-type channel blocker. In the presence of only $\mathrm{Ca}^{++}$in the bath at a concentration of $0.1 \mathrm{mM}, \mathrm{RD}$ was not evoked (Figure 10Be, $\mathrm{Ca}^{++}$, original voltage tracings before and after isradipine are not shown).

Separate bath application of T- and L-type channel blockers eliminated the inhibitory effect of $\mathrm{Ca}^{++}$on $\mathrm{RD}$, provided that the $\mathrm{Ca}^{++}$concentration in the extracellular solution did not exceed $0.1 \mathrm{mM}$. Therefore, we simultaneously applied T-type (NNC 55-0396, $50 \mu \mathrm{M}$ ) and L-type (isradipine, $10 \mu \mathrm{M}$ ) blockers to the bath and examined their effects on RD. RD could not be evoked using the standard current-clamp protocol (compare Figure 1Aa) in the presence of $\mathrm{Ca}^{++}(0.1 \mathrm{mM})$ and the absence of blockers in the bath. When $0.1 \mathrm{mM} \mathrm{Ca}^{++}$was applied to the extracellular solution together with these two channel blockers, typical RD was evoked $(561.3 \pm 29.7 \mathrm{~ms}, n=6)$. In the presence of $\mathrm{Ca}^{++}$at concentrations of $0.3 \mathrm{mM}$ and higher in the bath, $\mathrm{RD}$ could not be evoked, despite the presence of the T- and L-type channel blockers (original voltage tracings not shown in the figures).

Stimulation of the calcium sensing receptor (CaSR) by $\mathrm{Ca}^{++}$has been found to activate BK channels (Vassilev et al., 1997; Chattopadhyay et al., 1999; Bandyopadhyay et al., 2007). Therefore, we tested whether inhibition of CaSR would lead to the inhibition of $\mathrm{BK}$ channels and enable $\mathrm{RD}$. In the presence of $0.1 \mathrm{mM}$ of $\mathrm{Ca}^{++}$and the absence of a CaSR inhibitor, RD could not be evoked (Figures 10Ca,b,d, $\mathrm{Ca}^{++}, n=10$ ). However, in the presence of a CaSR blocker (NPS 2143, $3 \mu \mathrm{M}$ ) and $0.1 \mathrm{mM}$ of $\mathrm{Ca}^{++}$in the bath, RD was evoked $(530.4 \pm 33.1 \mathrm{~ms}$; Figures 10Cc,d, $\mathrm{Ca}^{++}+$NPS 2143, $\left.n=10\right)$. At a higher concentration of $\mathrm{Ca}^{++}(0.3 \mathrm{mM}$ and above $), \mathrm{RD}$ could not be evoked, despite the presence of a CaSR blocker.

The above results indicate that $\mathrm{Ca}^{++}$activating $\mathrm{BK}$ channels and attenuating $\mathrm{Na}^{+}$-dependent $\mathrm{RD}$ enters the cell through voltage-gated $\mathrm{Ca}^{++}$channels, including $\mathrm{T}$ - and L-type $\mathrm{Ca}^{++}$ channels.

\section{Effects of PKC and $A \beta_{1-42}$ on RD}

Activation of PKC inhibits BK channels (Shipston and Armstrong, 1996; Schubert and Nelson, 2001; Tian and Laychock, 2001; Kizub et al., 2010; Zhou et al., 2010; van Welie and du Lac, 2011). Therefore, we tested the effects of a membrane-permeable PKC activator (PMA, $1 \mu \mathrm{M}$ ) applied to the extracellular solution on RD. In the absence of PMA and the presence of $\mathrm{Ca}^{++}$in the extracellular solution $(1 \mathrm{mM}), \mathrm{RD}$ could not be evoked (Figures 11Aa,b,e, $\mathrm{Ca}^{++}, n=9$ ). However, in the same neurons, RD was evoked after a $15-\mathrm{min}$ bath application of PMA, despite the extracellular presence of $1 \mathrm{mM}$ of $\mathrm{Ca}^{++}$ (Figure 11Ac). The duration of RD evoked in the presence of PMA (449.9 $\pm 94.7 \mathrm{~ms}$, Figure 11Ae, $\mathrm{Ca}^{++}+$PMA, $\left.n=9\right) \mathrm{did}$ not differ from the duration of $\mathrm{RD}$ evoked in the absence of $\mathrm{Ca}^{++}$ in the extracellular solution $(564.3 \pm 39.6 \mathrm{~ms}, n=192, p>0.05$, 


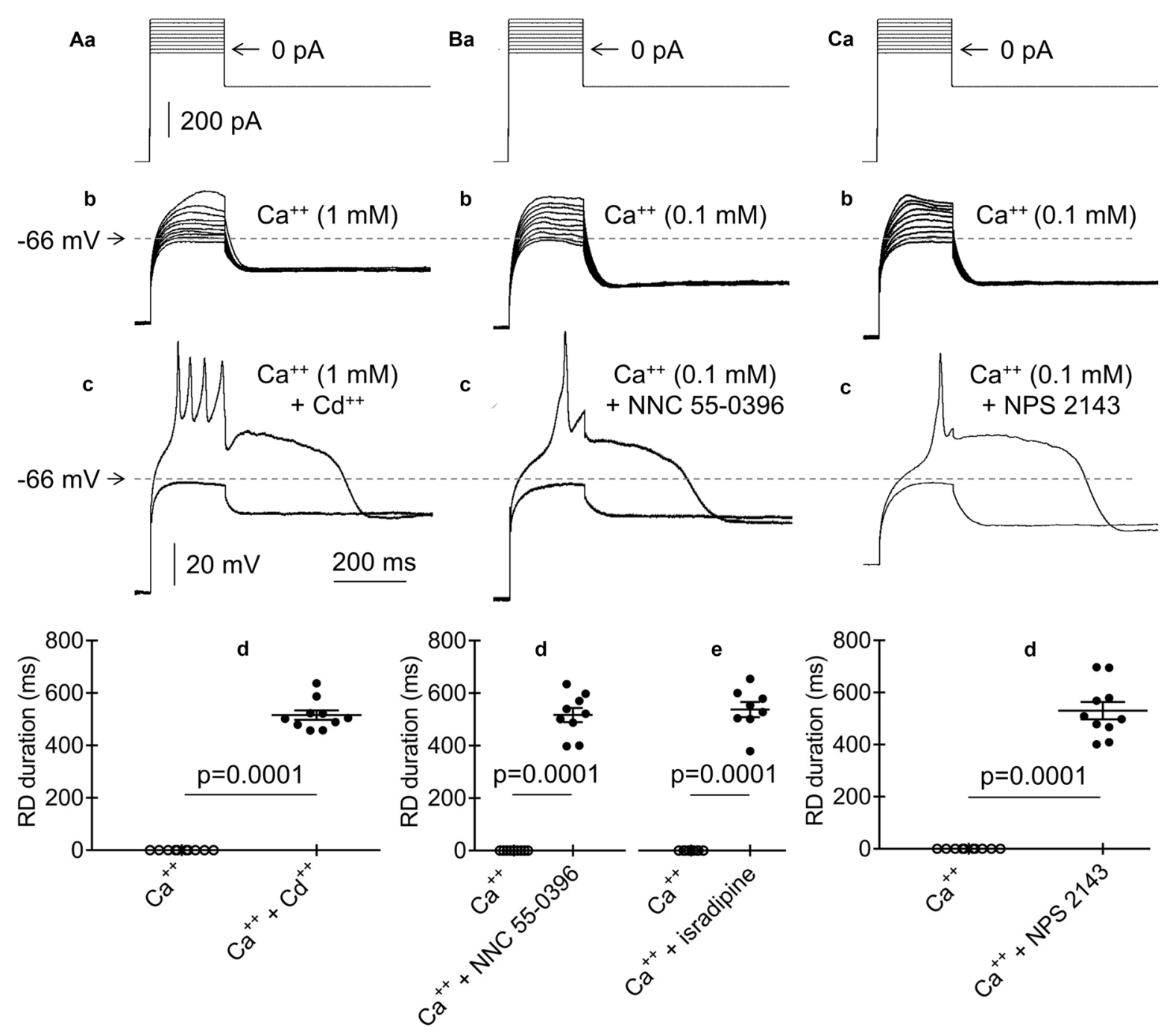

FIGURE 10 | Effects of $\mathrm{Cd}^{++}$, NNC 55-0396, isradipine and NPS 2143 on RD. (Aa) Current protocol applied to evoke voltage changes shown in (b,c) (compare Figure 1Aa). (b) RD was not evoked in the presence of $\mathrm{Ca}^{++}(1 \mathrm{mM})$ and the absence of $\mathrm{Cd}^{++}$in the bath in response to 200 -ms current pulses from $-20 \mathrm{pA}$ to $+160 \mathrm{pA}$. (c) RD evoked by a threshold 200-ms current pulse to $0 \mathrm{pA}$ in the bath presence of $\mathrm{Ca}^{++}(1 \mathrm{mM})$ and $\mathrm{Cd}^{++}(50 \mu \mathrm{M})$. (d) Absence of the RD in the bath in the presence of only $\mathrm{Ca}^{++}\left(\mathrm{Ca}^{++}, 1 \mathrm{mM}\right)$. RD could be evoked in the bath in the presence of $\mathrm{Ca}^{++}(1 \mathrm{mM})$ together with $\mathrm{Cd}^{++}\left(50 \mu \mathrm{M}, \mathrm{Ca}^{++}+\mathrm{Cd}^{++}\right)$. (Ba) Current protocol applied to evoke voltage changes shown in (b,c) (compare Figure 1Aa). (b) RD was not evoked in the presence of $\mathrm{Ca}^{++}(0.1 \mathrm{mM})$ in the bath in response to 200 -ms current pulses from $-20 \mathrm{pA}$ to $+160 \mathrm{pA}$. (c) RD evoked by a threshold 200 -ms current pulse to $0 \mathrm{pA}$ in the presence of $\mathrm{Ca}^{++}(0.1 \mathrm{mM})$ together with the

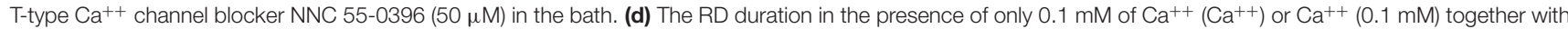
the T-type channel blocker NNC 55-0396 $(50 \mu \mathrm{M})\left(\mathbf{d}, \mathrm{Ca}^{++}+\right.$NNC 55-0396) in the extracellular solution. (e) The RD duration in the presence of only $\mathrm{Ca}^{++}\left(\mathrm{Ca}^{++}\right.$, $0.1 \mathrm{mM})$ or $\mathrm{Ca}^{++}(0.1 \mathrm{mM})$ together with the L-type channel blocker isradipine $\left(10 \mu \mathrm{M} ; \mathrm{Ca}^{++}+\right.$isradipine) in the extracellular solution. (Ca) Current protocol applied to evoke voltage changes shown in (b,c) (compare Figure 1Aa). (b) RD was not evoked in the presence of only $\mathrm{Ca}^{++}(0.1 \mathrm{mM})$ in the bath in response to 200 -ms current pulses from $-20 \mathrm{pA}$ to $+160 \mathrm{pA}$. (c) RD was evoked in response to a 200-ms threshold current pulse to $0 \mathrm{pA}$ in the presence of $\mathrm{Ca}^{++}(0.1 \mathrm{mM})$ together with calcium sensing receptor (CaSR) blocker (NPS 2143, $3 \mu \mathrm{M}$ ) in the bath. (d) The RD was not evoked in the presence of only $0.1 \mathrm{mM}^{-1} \mathrm{Ca}^{++}\left(\mathrm{Ca}^{++}\right)$. RD duration in the bath presence $\mathrm{Ca}^{++}(0.1 \mathrm{mM})$ together with NPS $2143(3 \mu \mathrm{M})\left(\mathrm{Ca}^{++}+\mathrm{NPS} 2143\right)$.

unpaired Student's $t$-test). As a control for the effect of PMA, an inactive analog of PMA ( $4 \alpha-$ PMA, $2 \mu \mathrm{M})$ was applied to the bath. $\mathrm{RD}$ could not be evoked with a $15-\mathrm{min}$ bath application of $\mathrm{Ca}^{++}$ $\left(1 \mathrm{mM}\right.$ ) and $4 \alpha$-PMA (Figures 11Aa,d,e, $\mathrm{Ca}^{++}+4 \alpha-\mathrm{PMA}, n=8$, $p=0.001$, unpaired Student's $t$-test).

$\mathrm{A} \beta_{1-42}$ has been shown to inhibit $\mathrm{BK}$ channels (Yamamoto et al., 2011). To examine the effect of $A \beta_{1-42}$ on RD, we added $10 \mu \mathrm{M}$ of $\mathrm{A} \beta_{1-42}$ to the recording pipette solution. $\mathrm{RD}$ could not be evoked at the beginning of cell "dialysis" with $\mathrm{A} \beta_{1-42}$ and in the presence of $\mathrm{Ca}^{++}(0.3 \mathrm{mM}$; Figures $11 \mathrm{Ba}, \mathbf{b})$ in the bath. However, RD could be evoked after 60 min of cell "dialysis" with $\mathrm{A} \beta_{1-42}$, despite the presence of $\mathrm{Ca}^{++}$in the extracellular solution $(0.3 \mathrm{mM}$, Figure $11 \mathrm{Bc})$. The RD duration under this condition was $235.9 \pm 53.5 \mathrm{~ms}$ (Figure 11Be, $\mathrm{Ca}^{++}+\mathrm{A} \beta_{1-42}, n=9$ ) and was significantly shorter ( $p<0.05$, unpaired Student's $t$-test) than the RD duration evoked under the control conditions in the 


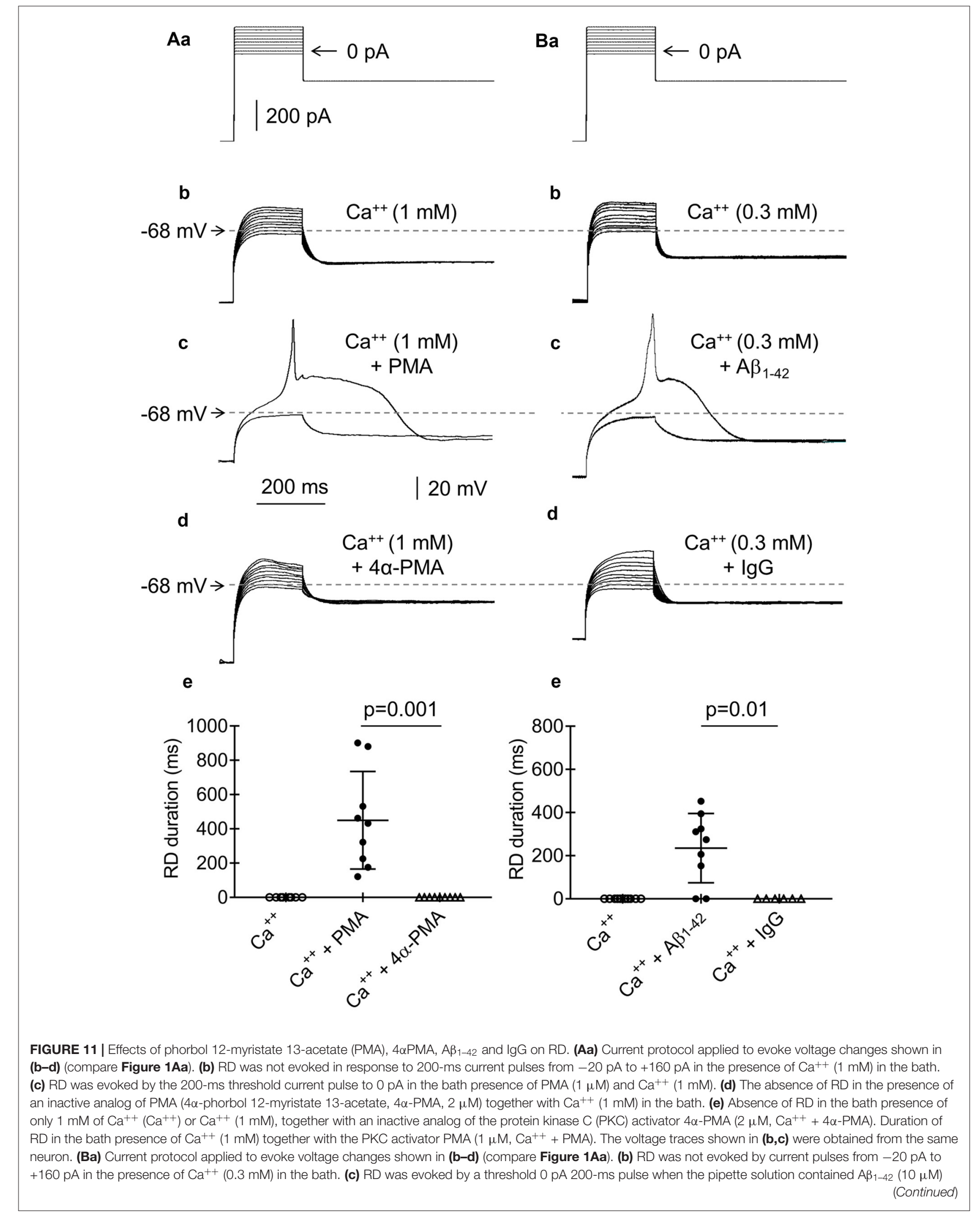


FIGURE 11 | Continued

and $\mathrm{Ca}^{++}(0.3 \mathrm{mM})$ was present in the bath. (d) Absence of $\mathrm{RD}$ when the pipette solution contained $\operatorname{lgG}(4 \mu \mathrm{g} / \mathrm{ml})$ and the extracellular solution contained $\mathrm{Ca}^{++}(0.3 \mathrm{mM})$. The voltage traces shown in $(\mathbf{b}, \mathbf{c})$ were obtained from the same neuron. (e) The absence of $\mathrm{RD}$ in the bath presence of $\mathrm{Ca}^{++}$ $(0.3 \mathrm{mM})$ only or in the bath presence of $\mathrm{Ca}^{++}(0.3 \mathrm{mM})$ together with $\operatorname{lgG}(4$ $\left.\mu \mathrm{g} / \mathrm{ml}, \mathrm{Ca}^{++}+\mathrm{lgG}\right)$ in the pipette solution. The RD was evoked in 7 from 9 tested neurons in the bath presence $\mathrm{Ca}^{++}(0.3 \mathrm{mM})$, together with the presence of $A \beta_{1-42}(10 \mu \mathrm{M})$ in the pipette solution $\left(\mathrm{Ca}^{++}+\mathrm{A} \beta_{1-42}\right)$.

absence of $\mathrm{Ca}^{++}$and any other biologically active compounds $(564.3 \pm 39.6 \mathrm{~ms}, n=192)$. At higher concentrations of $\mathrm{Ca}^{++}$ in the bath, $\mathrm{RD}$ was not evoked, despite the presence of $\mathrm{A} \beta_{1-42}$ in the pipette solution. As a control for the effect of $A \beta_{1-42}$, the normal IgG antibody $(4 \mu \mathrm{g} / \mathrm{ml})$ was applied to the recording pipette solution. After 60 min of cell "dialysis" with IgG in the presence of $\mathrm{Ca}^{++}(0.3 \mathrm{mM})$ in the bath, RD was not evoked (Figures 11Ba,d,e, $\mathrm{Ca}^{++}+\mathrm{IgG}, n=6, p=0.01$, unpaired Student's $t$-test).

\section{Repetitive Depolarizations Evoked During the RD Plateau}

In the presence of $\mathrm{Ca}^{++}$and the absence of TTX in the extracellular solution, typical action potentials were evoked during the current steps (Figure 2B). In the presence of TTX $(0.5$ or 1.0 or $10.0 \mu \mathrm{M})$ and the absence of $\mathrm{Ca}^{++}$, smallamplitude broad single (for example Figures 4D, 10Cc, 11Ac,Bc) or repetitive (spikelets, for example Figures $1 \mathrm{Ab}, 4 \mathrm{~B}, 5 \mathrm{Ac}, 6 \mathrm{Bb}, \mathrm{c}$, $\mathbf{8 B a}, \mathbf{b}, 10 \mathrm{Ac})$ depolarizations were observed at the beginning of RD (compare with Deisz, 1996). When $\mathrm{Na}^{+}$was replaced with choline-Cl in the extracellular solution, TTX-resistant repetitive depolarizations were not evoked, irrespective of the 200-ms current step amplitude (Figure 4C). Nav1.5 and Nav1.8 are TTX-resistant and voltage-dependent $\mathrm{Na}^{+}$currents that might potentially be responsible for these repetitive depolarizations. Nav1.5 channel currents can be blocked by high concentrations of TTX (Maier et al., 2003; Catterall et al., 2005). Nav1.8 channel currents are blocked by A803467 (Jarvis et al., 2007), A887826 (Zhang et al., 2010), or PF-01247324 (Payne et al., 2015). Bath application of TTX $(10 \mu \mathrm{M})$, A803467 $(1 \mu \mathrm{M})$, A887826 $(10 \mu \mathrm{M})$, or PF-01247324 (3 $\mu \mathrm{M})$ did not abolish either $\mathrm{RD}$ or the small-amplitude repetitive depolarizations evoked during RD (not shown). The properties of these TTX-resistant small repetitive depolarizations were not further investigated.

\section{DISCUSSION}

In this study, layer $\mathrm{V}$ mPFC pyramidal neurons were synaptically isolated due to the bath presence of GABAergic and glutamatergic transmission blockers and a voltage-gated $\mathrm{Na}^{+}$ channel blocker (TTX). In the tested neurons, two membrane currents were concomitantly activated after the hyperpolarizing step: a. a low-threshold, TTX-resistant inward $\mathrm{Na}^{+}$current that evoked $\mathrm{RD}$; and $\mathrm{b}$. an outward $\mathrm{K}^{+}$current through $\mathrm{BK}$ channels that opposes $\mathrm{Na}^{+}$-dependent depolarization. $\mathrm{RD}$ was observed after preventing $\mathrm{BK}$ channel activation. The $\mathrm{RD}$ amplitude was
$30 \mathrm{mV}$ above the resting membrane potential level $(-68 \mathrm{mV})$, and it lasted $560 \mathrm{~ms}$ under our experimental conditions.

\section{Mechanism of Hyperpolarization Required to Evoke RD}

$\mathrm{Na}^{+}$-dependent $\mathrm{RD}$ was evoked in pyramidal neurons after a hyperpolarizing voltage step below $-80 \mathrm{mV}$, if $\mathrm{BK}$ channels were inhibited. Hyperpolarization of this magnitude was recorded in $\mathrm{mPFC}$ pyramidal neurons in experiments resembling physiological conditions, such as during in vitro membrane potential recordings with sharp microelectrodes (Lavin and Grace, 2001; O’Donnell, 2003; Valenti and Grace, 2009). Moreover, hyperpolarization below $-80 \mathrm{mV}$ can be elicited in these neurons by electrical stimulation of the entorhinal cortex (Valenti and Grace, 2009), locus coeruleus (Branchereau et al., 1996), or CA1 subiculum (Thierry et al., 2000) or through activation of serotoninergic receptors (Beique et al., 2004; Goodfellow et al., 2009). Marked hyperpolarization can also be evoked by GABA released from interneurons activated by acetylcholine (Aracri et al., 2010) or serotonin (Cozzi and Nichols, 1996; Abi-Saab et al., 1999).

\section{BK Channel Inhibition Is Required to Trigger RD}

We obtained three lines of evidence indicating that $\mathrm{RD}$ can be evoked in the absence of outward $\mathrm{K}^{+}$current activation through BK channels. (1) RD could be evoked after bath depletion of $\mathrm{Ca}^{++}$. The removal of $\mathrm{Ca}^{++}$from the extracellular solution decreases the baseline $\mathrm{Ca}^{++}$concentration in the cytoplasm of both neurons (Magee et al., 1996; Pinilla et al., 2005; Cheek and Thorn, 2006; Nichols et al., 2007) and nonneuronal cells (Mignen et al., 2017). Reducing the concentration of $\mathrm{Ca}^{++}$in the cytoplasm leads to a marked increase in the voltage threshold of BK channels (Berkefeld and Fakler, 2013). (2) RD could be evoked in the presence of a selective BK channel blocker (paxilline) in the bath, despite the presence of $\mathrm{Ca}^{++}$in the extracellular solution. (3) Finally, RD could be evoked when the tested cells were loaded with the $\mathrm{Ca}^{++}$chelator BAPTA, despite the extracellular presence of $\mathrm{Ca}^{++}$. BAPTA eliminates free $\mathrm{Ca}^{++}$from the cytoplasm and considerably elevates the voltage activation threshold of BK channels (Fakler and Adelman, 2008).

The activation of CaSR by $\mathrm{Ca}^{++}$leads to the activation of BK channels (Vassilev et al., 1997; Chattopadhyay et al., 1999; Bandyopadhyay et al., 2007). Conversely, blockade of CaSR should lead to a decrease in BK channel activity. Indeed, we found that in the presence of a CaSR blocker, $\mathrm{RD}$ could be evoked, provided that the concentration of $\mathrm{Ca}^{++}$ in the extracellular solution did not exceed $0.1 \mathrm{mM}$. This finding supports the concept that activation of $\mathrm{BK}$ channels (in this case secondary to CaSR activation) is responsible for suppression of RD.

\section{BK Channel Inhibition Under Physiological and Pathophysiological Conditions}

The activation of PKC inhibits BK channels (Shipston and Armstrong, 1996; Schubert and Nelson, 2001; 
Tian and Laychock, 2001; Kizub et al., 2010; Zhou et al., 2010; van Welie and du Lac, 2011). In our study, RD could be evoked during activation of PKC, despite the presence of $\mathrm{Ca}^{++}$ $(1 \mathrm{mM})$ in the extracellular solution.

In our study, depletion of $\mathrm{Ca}^{++}$from the extracellular solution was an effective means of enabling RD. RD was blocked in the presence of $\mathrm{Ca}^{++}$in the bath at concentrations of $0.1 \mathrm{mM}$ or higher. A decrease in the $\mathrm{Ca}^{++}$concentration in the extracellular solution may be caused by displacement of $\mathrm{Ca}^{++}$ from the extracellular solution to the cytoplasm of glial cells and neurons.

The resting concentration of free $\mathrm{Ca}^{++}$in the cerebrospinal fluid is $1.1 \mathrm{mM}$ (Nilsson et al., 1993, 1996; Hartig et al., 2001). During neuronal activity, the concentration of $\mathrm{Ca}^{++}$ in the synaptic cleft drops to $0.3 \mathrm{mM}$ (Vassilev et al., 1997; Egelman and Montague, 1998, 1999; Rusakov et al., 1998) and to $0.1 \mathrm{mM}$ locally in the cerebrospinal fluid (Nicholson et al., 1978; Benninger et al., 1980; Heinemann and Pumain, 1980; Krnjević et al., 1982; Pumain et al., 1985). Theoretical calculations indicate that during neuronal activity, the $\mathrm{Ca}^{++}$ concentration in the cerebrospinal fluid decreases locally to $0 \mathrm{mM}$ (Egelman and Montague, 1998, 1999). Low levels of $\mathrm{Ca}^{++}$in the extracellular solution are maintained for several seconds due to the relatively small volume of the cerebrospinal fluid in relation to total brain volume (less than $20 \%$; Rusakov et al., 1998) and due to the very slow diffusion of $\mathrm{Ca}^{++}$ in the cerebrospinal fluid (Kullmann et al., 1999). Therefore, in theory, a $\mathrm{Ca}^{++}$level of zero can be attained locally in the cerebrospinal fluid, thus enabling $\mathrm{RD}$. The results of our study also indicate that incomplete depletion of $\mathrm{Ca}^{++}$from the extracellular solution together with additional manipulations, such as the intracellular presence $A \beta_{1-42}$, can also promote the emergence of RD.

\section{Mechanism of BK Channel Activation Following Hyperpolarization}

$\mathrm{RD}$ was not visible at physiological $\mathrm{Ca}^{++}$concentrations in the extracellular solution due to concomitant activation of the outward $\mathrm{K}^{+}$current through BK channels, raising the question of how BK channels are activated following the hyperpolarizing voltage step to oppose the $\mathrm{Na}^{+}$inward current and suppress $\mathrm{RD}$. At resting $\mathrm{Ca}^{++}$levels in the cytoplasm $(\sim 100-200 \mathrm{nM}$, for a review, Clapham, 2007), the voltage threshold of BK channels is in the range of the positive membrane potential and well above the resting membrane potential. Therefore, at rest, BK channels are not constitutively active in pyramidal neurons (Bock and Stuart, 2016). This result was confirmed in our study because bath application of paxilline did not evoke depolarization in the tested pyramidal neurons, suggesting the absence of a constitutive outward $\mathrm{K}^{+}$current through BK channels.

In the presence of the unselective voltage-gated $\mathrm{Ca}^{++}$blocker $\mathrm{Cd}^{++}$(Neumaier et al., 2015), RD could occur, despite the presence of $\mathrm{Ca}^{++}$at a physiological concentration $(1 \mathrm{mM})$ in the bath. This result suggests that an inward $\mathrm{Ca}^{++}$current through voltage-dependent channels is responsible for $\mathrm{BK}$ channel activation and $\mathrm{RD}$ suppression. Two low-threshold and voltage-dependent $\mathrm{Ca}^{++}$currents that may be activated when the hyperpolarizing voltage step returns to the resting membrane potential level have been described: T-type $\mathrm{Ca}^{++}$ currents and the recently described low-threshold L-type $\mathrm{Ca}^{++}$ currents.

Layer $\mathrm{V}$ cortical neurons express low-threshold, voltagedependent, fast-inactivating T-type $\mathrm{Ca}^{++}$channels (Sayer et al., 1990; de la Peña and Geijo-Barrientos, 1996; Craig et al., 1999; McKay et al., 2006). T-type channels are functionally (Smith et al., 2002) and structurally (Engbers et al., 2013b; Rehak et al., 2013) coupled to BK channels (Turner and Zamponi, 2014) and are largely inactivated at the resting membrane potential. Therefore, membrane hyperpolarization and subsequent depolarization could de-inactivate T-type channels (Molineux et al., 2006; Zamponi et al., 2010). Additionally, slowly inactivating, low-threshold L-type $\mathrm{Ca}^{++}$ channels (Magee et al., 1996; Lipscombe et al., 2004; Navedo et al., 2005; Kolaj et al., 2016), which form complexes with BK channels (Grunnet and Kaufmann, 2004; Guéguinou et al., 2014), have been described in pyramidal neurons. Our data indicate that at $\mathrm{Ca}^{++}$concentrations of $0.1 \mathrm{mM}$ in the bath, $\mathrm{RD}$ cannot be evoked. However, after separate or simultaneous blockade of Land T-type $\mathrm{Ca}^{++}$channels, $\mathrm{RD}$ is evoked, despite the presence of $0.1 \mathrm{mM}$ of $\mathrm{Ca}^{++}$in the extracellular solution. However, RD could not be evoked, despite the presence of L- and T-type $\mathrm{Ca}^{++}$channel blockers at higher $\mathrm{Ca}^{++}$concentrations in the extracellular solution.

Altogether, our results indicate that physiological concentrations of $\mathrm{Ca}^{++}$in the extracellular solution have an inhibitory effect on $\mathrm{RD}$, which was completely abolished in the presence of $\mathrm{Cd}^{++}$in the bath and only partially eliminated after blockade of $\mathrm{T}$ - and L-type channels. Therefore, in addition to $\mathrm{T}$ - and L-type channels, $\mathrm{Ca}^{++}$likely enters the cytoplasm through as yet undefined low-threshold and voltage-dependent $\mathrm{Ca}^{++}$channels after the hyperpolarizing voltage step.

\section{Mechanism of the Plateau-Like Depolarization During RD}

The inward $\mathrm{Na}^{+}$current was responsible for $\mathrm{RD}$ because the latter was abolished after $\mathrm{Na}^{+}$depletion from the extracellular solution. The involvement of HCN and NALCN channels, which are also permeable to $\mathrm{Na}^{+}$, was excluded as the source of the inward $\mathrm{Na}^{+}$current.

The following features suggest that activation of Nav1.9 channels might be responsible for the inward $\mathrm{Na}^{+}$ current and RD in the tested neurons. (1) The effector responsible for $\mathrm{RD}$ was permeable to $\mathrm{Na}^{+}$. (2) RD was blocked by the presence of an anti-Nav1.9 antibody in the intracellular solution. (3) Similar to the Nav1.9 channel currents in neurons of the dorsal root ganglia (DRG; Coste et al., 2004; Dib-Hajj and Waxman, 2015) and mPFC pyramidal neurons (Gawlak et al., 2017), RD was resistant to TTX. (4) The voltage threshold of $\mathrm{RD}$ was close to the resting membrane potential, similar to Nav1.9 channel currents in DRG neurons (Coste et al., 2004; Dib-Hajj and Waxman, 2015) and mPFC pyramidal neurons (Gawlak et al., 2017). (5) The RD threshold was reduced in the presence of $\mathrm{F}^{-}$, similar to the activation 
threshold of Nav1.9 channels in DRG neurons (Coste et al., 2004). (6) Steady-state inactivation of RD was removed by membrane hyperpolarization to $-80 \mathrm{mV}$, similar to the behavior of Nav1.9 currents, which were de-inactivated at $-80 \mathrm{mV}$ in DRG neurons (Coste et al., 2004; Dib-Hajj and Waxman, 2015) and in mPFC pyramidal neurons (Gawlak et al., 2017). (7) It was recently demonstrated that Nav1.9 channels are present in the mPFC (Gawlak et al., 2017; Radzicki et al., 2017), including in layer V pyramidal neurons (Kurowski et al., 2015). (8) Nav1.9 channels undergo slow inactivation, which is removed by cell membrane hyperpolarization (Rugiero et al., 2003; Coste et al., 2004; Maingret et al., 2008; Lin et al., 2016). This finding agrees with the assumption that Nav1.9 channel current is responsible for $\mathrm{RD}$ because $\mathrm{RD}$ could be evoked only after a prior hyperpolarizing step below $-81 \mathrm{mV}$.

mPFC pyramidal neurons projecting to subcortical structures show small RD after a hyperpolarizing current step. In pyramidal neurons projecting to the cortex, $\mathrm{RD}$ was not found. The $\mathrm{RD}$ described by others depended on $\mathrm{Na}^{+}$current flowing through HCN channels (Dembrow et al., 2010; Gee et al., 2012), while the RD described in our study had a much larger amplitude $(30 \mathrm{mV})$ than the $\mathrm{RD}$ described in other studies $(<1 \mathrm{mV})$ and depended on the activation of TTX-resistant, low-threshold $\mathrm{Na}^{+}$current, was not blocked by HCN channel blockers and was expressed in an overwhelming majority of tested pyramidal neurons. Therefore, it seems that the RD described by others was produced by different mechanisms than the $\mathrm{RD}$ depicted in our study.

\section{Significance of RD}

1. The present study suggests that inhibition of BK channels due to PKC activation enabled $\mathrm{Na}^{+}$-dependent $\mathrm{RD}$, despite the presence of a physiological concentration of $\mathrm{Ca}^{++}$in the extracellular solution. PKC is an effector of numerous transduction systems controlled by metabotropic receptors (Katritch et al., 2013). This finding raises the possibility that activation of metabotropic receptors and PKC-linked transduction pathways enable RD.

2. $\mathrm{A} \beta_{1-42}$ accumulates intracellularly in the neurons of Alzheimer's disease patients (Takahashi et al., 2002) and in the brains of Alzheimer's disease model mice (Oddo et al., 2003; Billings et al., 2005). In our study, application of $A \beta_{1-42}$ to the cytoplasm of pyramidal neurons enabled $R D$, despite the presence of $0.3 \mathrm{mM}$ of $\mathrm{Ca}^{++}$in the bath. This finding indicates the potential existence of positive feedback in brains with dementia. When the $\mathrm{Ca}^{++}$concentration drops to $0.3 \mathrm{mM}$ in the cerebrospinal fluid (due to an increase in neuronal activity), $\mathrm{RD}$ appears and further enhances neuronal activity. This phenomenon may explain the mechanism responsible for the observed increase in neuronal activity in patients with senile dementia (Ferreri et al., 2003).

3. Depletion of $\mathrm{Ca}^{++}$from the extracellular solution occurs during rapid neuronal discharge in seizures (Yaari et al., 1983; Heinemann and Hamon, 1986; Han et al., 2015; Nardone et al., 2016). Additionally, the occurrence of seizures is supported by the decrease in $\mathrm{Ca}^{++}$ion concentration in the cerebrospinal fluid (Yaari et al., 1983; Heinemann and Hamon, 1986; Han et al., 2015; Nardone et al., 2016), suggesting that in quiescent neurons, located close to the repetitively firing neurons, $\mathrm{RD}$ and activity increases can be evoked. The activity increases in quiescent neurons can be induced, providing that they are in the range of low $\mathrm{Ca}^{++}$concentration in the cerebrospinal fluid and they receive inhibitory input. Moreover, our study indicates that increased activity in such neurons can be favored by either inhibition of T- or L-type $\mathrm{Ca}^{++}$channels or by blockade of BK channels (e.g., by PKC activation), and can be prevented by inhibition of persistent and TTX-resistant inward $\mathrm{Na}^{+}$ current.

4. Up- and down-states are defined as intermittent shifts of membrane potential from hyperpolarization (down-state) to depolarization (up-state) in cortical and subcortical neurons (typically lasting a few $100 \mathrm{~ms}$ each, Wilson and Kawaguchi, 1996; McCormick et al., 2003). During downstate, the membrane potential can drop below $-80 \mathrm{mV}$ in $\mathrm{mPFC}$ pyramidal neurons (e.g., Figure 1 in Lewis and O'Donnell, 2000). Slow membrane potential oscillations in mPFC pyramidal neurons are thought to be dependent on recurrent networks of local neuronal circuits (McCormick et al., 2003), intrinsic neuronal properties (Seamans and Yang, 2004), or synaptic inputs into mPFC pyramidal neurons (O'Donnell, 2003). One may presume that low-threshold, TTX-resistant, and voltage-dependent inward $\mathrm{Na}^{+}$current can be activated and can support the up-state when the membrane potential shifts from the down-state to the upstate. However, such reinforcement of the up-state can occur only if it is accompanied by inhibition of BK channels, such as during PKC activation or in the intracellular presence of $\mathrm{A} \beta_{1-42}$.

5. One feature of prefrontal cortex pyramidal neurons is the capacity to generate prolonged depolarizations with a series of action potentials at the depolarization peak (persistent activity) and lasting markedly longer than the triggering stimulus (for review, see Galloway et al., 2008; Riley and Constantinidis, 2016). Several mechanisms have been proposed to be responsible for the generation of the prolonged depolarization, related preferentially to the excitatory input to the mPFC pyramidal neurons. For example, it was demonstrated that depolarization may depend on the glutaminergic and dopaminergic input to pyramidal neurons from distant cells (Lewis and O'Donnell, 2000; Seamans et al., 2003). Moreover, it was indicated that prolonged depolarizations may be dependent on local circuits (McCormick et al., 2003; Haider et al., 2006) or intrinsic properties of these neurons (Zylberberg and Strowbridge, 2017). It is most likely that several mechanisms are responsible for prolonged depolarization and persistent activity. Our study shows that RD evoked after hyperpolarization resembles the prolonged depolarizations elicited by excitatory input to mPFC pyramidal cells in terms of amplitude, duration and the repetitive spikes seen during the depolarization plateau. However, the 
mechanisms of prolonged depolarizations described by others and of $\mathrm{RD}$ described in our study are triggered by different mechanisms (hyperpolarization vs. depolarization); moreover, the mechanisms of their creation are also different.

\section{AUTHOR CONTRIBUTIONS}

PK and PS conceived and designed the experiments, discussed the data and wrote the manuscript. PK performed the

\section{REFERENCES}

Abi-Saab, W. M., Bubser, M., Roth, R. H., and Deutch, A. Y. (1999). $5-\mathrm{HT}_{2}$ receptor regulation of extracellular GABA levels in the prefrontal cortex. Neuropsychopharmacology 20, 92-96. doi: 10.1016/s0893-133x(98) 00046-3

Albert, P. R., Vahid-Ansari, F., and Luckhart, C. (2014). Serotonin-prefrontal cortical circuitry in anxiety and depression phenotypes: pivotal role of preand post-synaptic 5- $\mathrm{HT}_{1 A}$ receptor expression. Front. Behav. Neurosci. 8:199. doi: 10.3389/fnbeh.2014.00199

Albertson, A. J., Yang, J., and Hablitz, J. J. (2011). Decreased hyperpolarizationactivated currents in layer 5 pyramidal neurons enhances excitability in focal cortical dysplasia. J. Neurophysiol. 106, 2189-2200. doi: 10.1152/jn.00164.2011

Aman, T. K., and Raman, I. M. (2007). Subunit dependence of Na channel slow inactivation and open channel block in cerebellar neurons. Biophys. J. 92, 1938-1951. doi: 10.1529/biophysj.106.093500

Anekonda, T. S., Quinn, J. F., Harris, C., Frahler, K., Wadsworth, T. L., and Woltjer, R. L. (2011). L-type voltage-gated calcium channel blockade with isradipine as a therapeutic strategy for Alzheimer's disease. Neurobiol. Dis. 41, 62-70. doi: 10.1016/j.nbd.2010.08.020

Aracri, P., Consonni, S., Morini, R., Perrella, M., Rodighiero, S., Amadeo, A., et al. (2010). Tonic modulation of GABA release by nicotinic acetylcholine receptors in layer V of the murine prefrontal cortex. Cereb. Cortex 20, 1539-1555. doi: 10.1093/cercor/bhp214

Bandyopadhyay, S., Jeong, K. H., Hansen, J. T., Vassilev, P. M., Brown, E. M., and Chattopadhyay, N. (2007). Calcium-sensing receptor stimulates secretion of an interferon- $\gamma$-induced monokine (CXCL10) and monocyte chemoattractant protein-3 in immortalized GnRH neurons. J. Neurosci. Res. 85, 882-895. doi: $10.1002 /$ jnr. 21177

Beique, J. C., Campbell, B., Perring, P., Hamblin, M. W., Walker, P., Mladenovic, L., et al. (2004). Serotonergic regulation of membrane potential in developing rat prefrontal cortex: coordinated expression of 5-hydroxytryptamine $(5-\mathrm{HT})_{1 A}, 5-\mathrm{HT}_{2 A}$, and 5- $\mathrm{HT}_{7}$ receptors. J. Neurosci. 24, 4807-4817. doi: 10.1523/JNEUROSCI.5113-03.2004

Benninger, C., Kadis, J., and Prince, D. A. (1980). Extracellular calcium and potassium changes in hippocampal slices. Brain Res. 187, 165-182. doi: 10.1016/0006-8993(80)90502-8

Berkefeld, H., and Fakler, B. (2013). Ligand-gating by $\mathrm{Ca}^{2+}$ is rate limiting for physiological operation of $\mathrm{BK}(\mathrm{Ca})$ channels. J. Neurosci. 33, 7358-7367. doi: 10.1523/JNEUROSCI.5443-12.2013

Bhattacharjee, A., Von Hehn, C. A., Mei, X., and Kaczmarek, L. K. (2005). Localization of the $\mathrm{Na}^{+}$-activated $\mathrm{K}^{+}$channel Slick in the rat central nervous system. J. Comp. Neurol. 484, 80-92. doi: 10.1002/cne.20462

Billings, L. M., Oddo, S., Green, K. N., Mcgaugh, J. L., and Laferla, F. M. (2005). Intraneuronal $A \beta$ causes the onset of early Alzheimer's disease-related cognitive deficits in transgenic mice. Neuron 45, 675-688. doi: 10.1016/j. neuron.2005.01.040

Bock, T., and Stuart, G. J. (2016). Impact of calcium-activated potassium channels on NMDA spikes in cortical layer 5 pyramidal neurons. J. Neurophysiol. 115, 1740-1748. doi: 10.1152/jn.01047.2015

Boehme, R., Uebele, V. N., Renger, J. J., and Pedroarena, C. (2011). Rebound excitation triggered by synaptic inhibition in cerebellar nuclear neurons is suppressed by selective T-type calcium channel block. J. Neurophysiol. 106, 2653-2661. doi: 10.1152/jn.00612.2011 experiments, analyzed the data and prepared the figures. KG executed some experiments.

\section{FUNDING}

This work was supported by the National Science Centre, Poland (grant number: 2015/17/N/NZ4/02889), the Medical University of Warsaw (grant numbers: FW5/PM1/16 and FW5/PM1/17/17), and the Innovative Economy Operational Programme (grant number: POIG.02.02.00-14-024/08-00).

Boone, A. N., Senatore, A., Chemin, J., Monteil, A., and Spafford, J. D. (2014). Gd3+ and calcium sensitive, sodium leak currents are features of weak membrane-glass seals in patch clamp recordings. PLoS One 9:e98808. doi: 10.1371/journal.pone.0098808

Branchereau, P., Van Bockstaele, E. J., Chan, J., and Pickel, V. M. (1996). Pyramidal neurons in rat prefrontal cortex show a complex synaptic response to single electrical stimulation of the locus coeruleus region: evidence for antidromic activation and GABAergic inhibition using in vivo intracellular recording and electron microscopy. Synapse 22, 313-331. doi: 10.1002/(sici)10982396(199604)22:4<313::aid-syn3>3.0.co;2-e

Campbell, C. A., Mackay, K. B., Patel, S., King, P. D., Stretton, J. L., Hadingham, S. J., et al. (1997). Effects of isradipine, an L-type calcium channel blocker on permanent and transient focal cerebral ischemia in spontaneously hypertensive rats. Exp. Neurol. 148, 45-50. doi: 10.1006/exnr.1997.6611

Catterall, W. A., Goldin, A. L., and Waxman, S. G. (2005). International Union of Pharmacology. XLVII. Nomenclature and structure-function relationships of voltage-gated sodium channels. Pharmacol. Rev. 57, 397-409. doi: 10.1124/pr. 57.4 .4

Chattopadhyay, N., Ye, C. P., Yamaguchi, T., Kerner, R., Vassilev, P. M., and Brown, E. M. (1999). Extracellular calcium-sensing receptor induces cellular proliferation and activation of a nonselective cation channel in U373 human astrocytoma cells. Brain Res. 851, 116-124. doi: 10.1016/s0006-8993(99) 02132-0

Cheek, T. R., and Thorn, P. (2006). A constitutively active nonselective cation conductance underlies resting $\mathrm{Ca}^{2+}$ influx and secretion in bovine adrenal chromaffin cells. Cell Calcium 40, 309-318. doi: 10.1016/j.ceca.2006.04.002

Clapham, D. E. (2007). Calcium signaling. Cell 131, 1047-1058. doi: 10.1016/j.cell. 2007.11.028

Cochet-Bissuel, M., Lory, P., and Monteil, A. (2014). The sodium leak channel, NALCN, in health and disease. Front. Cell. Neurosci. 8:132. doi: 10.3389/fncel. 2014.00132

Coste, B., Osorio, N., Padilla, F., Crest, M., and Delmas, P. (2004). Gating and modulation of presumptive NaV1.9 channels in enteric and spinal sensory neurons. Mol. Cell. Neurosci. 26, 123-134. doi: 10.1016/j.mcn.2004.01.015

Cozzi, N. V., and Nichols, D. E. (1996). 5-HT2A receptor antagonists inhibit potassium-stimulated $\gamma$-aminobutyric acid release in rat frontal cortex. Eur. J. Pharmacol. 309, 25-31. doi: 10.1016/0014-2999(96)00325-1

Craig, P. J., Beattie, R. E., Folly, E. A., Banerjee, M. D., Reeves, M. B., Priestley, J. V., et al. (1999). Distribution of the voltage-dependent calcium channel $\alpha 1 G$ subunit mRNA and protein throughout the mature rat brain. Eur. J. Neurosci. 11, 2949-2964. doi: 10.1046/j.1460-9568.1999.00711.x

de la Peña, E., and Geijo-Barrientos, E. (1996). Laminar localization, morphology, and physiological properties of pyramidal neurons that have the low-threshold calcium current in the guinea-pig medial frontal cortex. J. Neurosci. 16, 5301-5311.

Deisz, R. A. (1996). A tetrodotoxin-insensitive [corrected] sodium current initiates burst firing of neocortical neurons. Neuroscience 70, 341-351. doi: 10.1016/0306-4522(95)00362-2

Dembrow, N. C., Chitwood, R. A., and Johnston, D. (2010). Projectionspecific neuromodulation of medial prefrontal cortex neurons. J. Neurosci. 30, 16922-16937. doi: 10.1523/JNEUROSCI.3644-10.2010

Dib-Hajj, S. D., and Waxman, S. G. (2015). Diversity of composition and function of sodium channels in peripheral sensory neurons. Pain 156, 2406-2407. doi: 10.1097/j.pain.0000000000000353 
Egelman, D. M., and Montague, P. R. (1998). Computational properties of peri-dendritic calcium fluctuations. J. Neurosci. 18, 8580-8589.

Egelman, D. M., and Montague, P. R. (1999). Calcium dynamics in the extracellular space of mammalian neural tissue. Biophys. J. 76, 1856-1867. doi: 10.1016/s0006-3495(99)77345-5

Engbers, J. D., Anderson, D., Zamponi, G. W., and Turner, R. W. (2013a). Signal processing by T-type calcium channel interactions in the cerebellum. Front. Cell. Neurosci. 7:230. doi: 10.3389/fncel.2013.00230

Engbers, J. D., Zamponi, G. W., and Turner, R. W. (2013b). Modeling interactions between voltage-gated $\mathrm{Ca}^{2+}$ channels and KCa1.1 channels. Channels 7, 524-529. doi: 10.4161/chan.25867

Faber, E. S. (2010). Functional interplay between NMDA receptors, SK channels and voltage-gated $\mathrm{Ca}^{2+}$ channels regulates synaptic excitability in the medial prefrontal cortex. J. Physiol. 588, 1281-1292. doi: 10.1113/jphysiol.2009. 185645

Fakler, B., and Adelman, J. P. (2008). Control of $\mathrm{K}_{\mathrm{Ca}}$ channels by calcium nano/microdomains. Neuron 59, 873-881. doi: 10.1016/j.neuron.2008.09.001

Fan, Y. P., Horn, E. M., and Waldrop, T. G. (2000). Biophysical characterization of rat caudal hypothalamic neurons: calcium channel contribution to excitability. J. Neurophysiol. 84, 2896-2903. doi: 10.1152/jn.2000.84.6.2896

Ferreri, F., Pauri, F., Pasqualetti, P., Fini, R., Dal Forno, G., and Rossini, P. M. (2003). Motor cortex excitability in Alzheimer's disease: a transcranial magnetic stimulation study. Ann. Neurol. 53, 102-108. doi: 10.1002/ana.10416

Forrest, M. D., Wall, M. J., Press, D. A., and Feng, J. (2012). The sodium-potassium pump controls the intrinsic firing of the cerebellar Purkinje neuron. PLoS One 7:e51169. doi: 10.1371/journal.pone.0051169

Galloway, E. M., Woo, N. H., and Lu, B. (2008). Persistent neural activity in the prefrontal cortex: a mechanism by which BDNF regulates working memory? Prog. Brain Res. 169, 251-266. doi: 10.1016/s0079-6123(07)00015-5

Gawlak, M., Szulczyk, B., Berlowski, A., Grzelka, K., Stachurska, A., Pelka, J., et al. (2017). Age-dependent expression of Nav1.9 channels in medial prefrontal cortex pyramidal neurons in rats. Dev. Neurobiol. 77, 1371-1384. doi: 10.1002/dneu.22537

Gee, S., Ellwood, I., Patel, T., Luongo, F., Deisseroth, K., and Sohal, V. S. (2012). Synaptic activity unmasks dopamine D2 receptor modulation of a specific class of layer V pyramidal neurons in prefrontal cortex. J. Neurosci. 32, 4959-4971. doi: 10.1523/JNEUROSCI.5835-11.2012

Goodfellow, N. M., Benekareddy, M., Vaidya, V. A., and Lambe, E. K. (2009). Layer II/III of the prefrontal cortex: inhibition by the serotonin 5-HT1A receptor in development and stress. J. Neurosci. 29, 10094-10103. doi: 10.1523/JNEUROSCI.1960-09.2009

Grenier, F., Timofeev, I., and Steriade, M. (1998). Leading role of thalamic over cortical neurons during postinhibitory rebound excitation. Proc. Natl. Acad. Sci. US A 95, 13929-13934. doi: 10.1073/pnas.95.23.13929

Grunnet, M., and Kaufmann, W. A. (2004). Coassembly of big conductance $\mathrm{Ca}^{2+}$-activated $\mathrm{K}^{+}$channels and L-type voltage-gated $\mathrm{Ca}^{2+}$ channels in rat brain. J. Biol. Chem. 279, 36445-36453. doi: 10.1074/jbc.M402254200

Grzelka, K., Kurowski, P., Gawlak, M., and Szulczyk, P. (2017). Noradrenaline modulates the membrane potential and holding current of medial prefrontal cortex pyramidal neurons via $\beta 1$-adrenergic receptors and $\mathrm{HCN}$ channels. Front. Cell. Neurosci. 11:341. doi: 10.3389/fncel.2017.00341

Guéguinou, M., Chantôme, A., Fromont, G., Bougnoux, P., Vandier, C., and Potier-Cartereau, M. (2014). KCa and $\mathrm{Ca}^{2+}$ channels: the complex thought. Biochim. Biophys. Acta 1843, 2322-2333. doi: 10.1016/j.bbamcr.2014.02.019

Gulledge, A. T., and Jaffe, D. B. (1998). Dopamine decreases the excitability of layer V pyramidal cells in the rat prefrontal cortex. J. Neurosci. 18, 9139-9151.

Haider, B., Duque, A., Hasenstaub, A. R., and McCormick, D. A. (2006). Neocortical network activity in vivo is generated through a dynamic balance of excitation and inhibition. J. Neurosci. 26, 4535-4545. doi: 10.1523/JNEUROSCI.5297-05.2006

Han, P., Trinidad, B. J., and Shi, J. (2015). Hypocalcemia-induced seizure: demystifying the calcium paradox. ASN Neuro 7:1759091415578050. doi: $10.1177 / 1759091415578050$

Harris, K. D., and Thiele, A. (2011). Cortical state and attention. Nat. Rev. Neurosci. 12, 509-523. doi: 10.1038/nrn3084

Hartig, W., Singer, A., Grosche, J., Brauer, K., Ottersen, O. P., and Brückner, G. (2001). Perineuronal nets in the rat medial nucleus of the trapezoid body surround neurons immunoreactive for various amino acids, calcium-binding proteins and the potassium channel subunit Kv3.1b. Brain Res. 899, 123-133. doi: 10.1016/s0006-8993(01)02211-9

Heinemann, U., and Hamon, B. (1986). Calcium and epileptogenesis. Exp. Brain Res. 65, 1-10. doi: 10.1007/978-3-642-70744-5_34

Heinemann, U., and Pumain, R. (1980). Extracellular calcium activity changes in cat sensorimotor cortex induced by iontophoretic application of aminoacids. Exp. Brain Res. 40, 247-250. doi: 10.1007/bf00237788

Jarvis, M. F., Honore, P., Shieh, C. C., Chapman, M., Joshi, S., Zhang, X. F., et al. (2007). A-803467, a potent and selective Nav1.8 sodium channel blocker, attenuates neuropathic and inflammatory pain in the rat. Proc. Natl. Acad. Sci. U S A 104, 8520-8525. doi: 10.1016/s1073-5437(08)70987-2

Kaczmarek, L. K. (2013). Slack, slick, and sodium-activated potassium channels. ISRN Neurosci. 2013:354262. doi: 10.1155/2013/354262

Katritch, V., Cherezov, V., and Stevens, R. C. (2013). Structure-function of the G protein-coupled receptor superfamily. Annu. Rev. Pharmacol. Toxicol. 53, 531-556. doi: 10.1146/annurev-pharmtox-032112-135923

Kirshner, H. S. (2014). Frontotemporal dementia and primary progressive aphasia, a review. Neuropsychiatr. Dis. Treat. 10, 1045-1055. doi: 10.2147/NDT. s38821

Kizub, I. V., Pavlova, O. O., Ivanova, I. V., and Soloviev, A. I. (2010). Protein kinase $\mathrm{C}$-dependent inhibition of $\mathrm{BK}_{\mathrm{Ca}}$ current in rat aorta smooth muscle cells following $\gamma$-irradiation. Int. J. Radiat. Biol. 86, 291-299. doi: 10.3109/09553000903564042

Kolaj, M., Zhang, L., and Renaud, L. P. (2016). L-type calcium channels and MAP kinase contribute to thyrotropin-releasing hormone-induced depolarization in thalamic paraventricular nucleus neurons. Am. J. Physiol. Regul. Integr. Comp. Physiol. 310, R1120-R1127. doi: 10.1152/ajpregu.00082.2016

Krey, R. A., Goodreau, A. M., Arnold, T. B., and Del Negro, C. A. (2010). Outward currents contributing to inspiratory burst termination in prebotzinger complex neurons of neonatal mice studied in vitro. Front. Neural Circuits 4:124. doi: 10.3389/fncir.2010.00124

Krnjević, K., Morris, M. E., Reiffenstein, R. J., and Ropert, N. (1982). Depth distribution and mechanism of changes in extracellular $\mathrm{K}^{+}$and $\mathrm{Ca}^{2+}$ concentrations in the hippocampus. Can. J. Physiol. Pharmacol. 60, 1658-1671. doi: 10.1139/y82-244

Książek, A., Ladno, W., Szulczyk, B., Grzelka, K., and Szulczyk, P. (2013). Properties of BK-type $\mathrm{Ca}^{++}$-dependent $\mathrm{K}^{+}$channel currents in medial prefrontal cortex pyramidal neurons in rats of different ages. Front. Cell. Neurosci. 7:185. doi: 10.3389/fncel.2013.00185

Kullmann, D. M., Min, M. Y., Asztely, F., and Rusakov, D. A. (1999). Extracellular glutamate diffusion determines the occupancy of glutamate receptors at CA1 synapses in the hippocampus. Philos. Trans. R. Soc. Lond. B Biol. Sci. 354, 395-402. doi: 10.1098/rstb.1999.0392

Kurowski, P., Gawlak, M., and Szulczyk, P. (2015). Muscarinic receptor control of pyramidal neuron membrane potential in the medial prefrontal cortex (mPFC) in rats. Neuroscience 303, 474-488. doi: 10.1016/j.neuroscience.2015. 07.023

Lavin, A., and Grace, A. A. (2001). Stimulation of D1-type dopamine receptors enhances excitability in prefrontal cortical pyramidal neurons in a state-dependent manner. Neuroscience 104, 335-346. doi: 10.1016/s03064522(01)00096-3

Lee, A. T., Gee, S. M., Vogt, D., Patel, T., Rubenstein, J. L., and Sohal, V. S. (2014). Pyramidal neurons in prefrontal cortex receive subtype-specific forms of excitation and inhibition. Neuron 81, 61-68. doi: 10.1016/j.neuron. 2013.10.031

Lewis, B. L., and O'Donnell, P. (2000). Ventral tegmental area afferents to the prefrontal cortex maintain membrane potential 'up' states in pyramidal neurons via D1 dopamine receptors. Cereb. Cortex 10, 1168-1175. doi: 10.1093/cercor/10.12.1168

Li, W. C., and Moult, P. R. (2012). The control of locomotor frequency by excitation and inhibition. J. Neurosci. 32, 6220-6230. doi: 10.1523/JNEUROSCI.6289-11.2012

Lin, Z., Santos, S., Padilla, K., Printzenhoff, D., and Castle, N. A. (2016). Biophysical and pharmacological characterization of Nav1.9 voltage dependent sodium channels stably expressed in HEK-293 cells. PLoS One 11:e0161450. doi: 10.1371/journal.pone.0161450

Lipscombe, D., Helton, T. D., and Xu, W. (2004). L-type calcium channels: the low down. J. Neurophysiol. 92, 2633-2641. doi: 10.1152/jn.00486.2004 
Lüthi, A., Bal, T., and McCormick, D. A. (1998). Periodicity of thalamic spindle waves is abolished by ZD7288, a blocker of Ih. J. Neurophysiol. 79, 3284-3289. doi: 10.1152/jn.1998.79.6.3284

Magee, J. C., Avery, R. B., Christie, B. R., and Johnston, D. (1996). Dihydropyridine-sensitive, voltage-gated $\mathrm{Ca}^{2+}$ channels contribute to the resting intracellular $\mathrm{Ca}^{2+}$ concentration of hippocampal CA1 pyramidal neurons. J. Neurophysiol. 76, 3460-3470. doi: 10.1152/jn.1996.76.5.3460

Maier, S. K., Westenbroek, R. E., Yamanushi, T. T., Dobrzynski, H., Boyett, M. R., Catterall, W. A., et al. (2003). An unexpected requirement for brain-type sodium channels for control of heart rate in the mouse sinoatrial node. Proc. Natl. Acad. Sci. U S A 100, 3507-3512. doi: 10.1073/pnas.2627986100

Maingret, F., Coste, B., Padilla, F., Clerc, N., Crest, M., Korogod, S. M., et al. (2008). Inflammatory mediators increase Nav1.9 current and excitability in nociceptors through a coincident detection mechanism. J. Gen. Physiol. 131, 211-225. doi: 10.1085/jgp.200709935

Marty, A., and Neher, E. (1995). "Tight-seal whole-cell recording," in SingleChannel Recording, eds B. Sakmann and E. Neher (New York, NY: Plenum Press), 31-52.

Marzo, A., Totah, N. K., Neves, R. M., Logothetis, N. K., and Eschenko, O. (2014). Unilateral electrical stimulation of rat locus coeruleus elicits bilateral response of norepinephrine neurons and sustained activation of medial prefrontal cortex. J. Neurophysiol. 111, 2570-2588. doi: 10.1152/jn.00920.2013

McCormick, D. A., Shu, Y., Hasenstaub, A., Sanchez-Vives, M., Badoual, M., and Bal, T. (2003). Persistent cortical activity: mechanisms of generation and effects on neuronal excitability. Cereb. Cortex 13, 1219-1231. doi: 10.1093/cercor/bhg104

McKay, B. E., McRory, J. E., Molineux, M. L., Hamid, J., Snutch, T. P., Zamponi, G. W., et al. (2006). $\mathrm{Ca}_{\mathrm{v}} 3$ T-type calcium channel isoforms differentially distribute to somatic and dendritic compartments in rat central neurons. Eur. J. Neurosci. 24, 2581-2594. doi: 10.1111/j.1460-9568.2006. 05136. $\mathrm{x}$

Mignen, O., Constantin, B., Potier-Cartereau, M., Penna, A., Gautier, M., Gueguinou, M., et al. (2017). Constitutive calcium entry and cancer: updated views and insights. Eur. Biophys. J. 46, 395-413. doi: 10.1007/s00249-0171216-8

Molineux, M. L., McRory, J. E., McKay, B. E., Hamid, J., Mehaffey, W. H., Rehak, R., et al. (2006). Specific T-type calcium channel isoforms are associated with distinct burst phenotypes in deep cerebellar nuclear neurons. Proc. Natl. Acad. Sci. U S A 103, 5555-5560. doi: 10.1073/pnas.0601261103

Nardone, R., Brigo, F., and Trinka, E. (2016). Acute symptomatic seizures caused by electrolyte disturbances. J. Clin. Neurol. 12, 21-33. doi: 10.3988/jcn.2016. 12.1.21

Navedo, M. F., Amberg, G. C., Votaw, V. S., and Santana, L. F. (2005). Constitutively active L-type $\mathrm{Ca}^{2+}$ channels. Proc. Natl. Acad. Sci. U S A 102, 11112-11117. doi: $10.1073 /$ pnas. 0500360102

Neske, G. T. (2016). The slow oscillation in cortical and thalamic networks: mechanisms and functions. Front. Neural Circuits 9:88. doi: 10.3389/fncir.2015. 00088

Neumaier, F., Dibué-Adjei, M., Hescheler, J., and Schneider, T. (2015). Voltagegated calcium channels: determinants of channel function and modulation by inorganic cations. Prog. Neurobiol. 129, 1-36. doi: 10.1016/j.pneurobio.2014. 12.003

Nichols, R. A., Dengler, A. F., Nakagawa, E. M., Bashkin, M., Paul, B. T., $\mathrm{Wu}$, J., et al. (2007). A constitutive, transient receptor potential-like $\mathrm{Ca}^{2+}$ influx pathway in presynaptic nerve endings independent of voltage-gated $\mathrm{Ca}^{2+}$ channels and $\mathrm{Na}^{+} / \mathrm{Ca}^{2+}$ exchange. J. Biol. Chem. 282, 36102-36111. doi: 10.1074/jbc.M706002200

Nicholson, C., ten Bruggencate, G., Stöckle, H., and Steinberg, R. (1978). Calcium and potassium changes in extracellular microenvironment of cat cerebellar cortex. J. Neurophysiol. 41, 1026-1039. doi: 10.1152/jn.1978.41.4.1026

Nilsson, P., Hillered, L., Olsson, Y., Sheardown, M. J., and Hansen, A. J. (1993). Regional changes in interstitial $\mathrm{K}^{+}$and $\mathrm{Ca}^{2+}$ levels following cortical compression contusion trauma in rats. J. Cereb. Blood Flow Metab. 13, 183-192. doi: $10.1038 / \mathrm{jcbfm} .1993 .22$

Nilsson, P., Laursen, H., Hillered, L., and Hansen, A. J. (1996). Calcium movements in traumatic brain injury: the role of glutamate receptor-operated ion channels. J. Cereb. Blood Flow Metab. 16, 262-270. doi: 10.1097/00004647199603000-00011
Oddo, S., Caccamo, A., Shepherd, J. D., Murphy, M. P., Golde, T. E., Kayed, R., et al. (2003). Triple-transgenic model of Alzheimer's disease with plaques and tangles: intracellular $A \beta$ and synaptic dysfunction. Neuron 39, 409-421. doi: 10.1016/S0896-6273(03)00434-3

O'Donnell, P. (2003). Dopamine gating of forebrain neural ensembles. Eur. J. Neurosci. 17, 429-435. doi: 10.1046/j.1460-9568.2003.02463.x

Payne, C. E., Brown, A. R., Theile, J. W., Loucif, A. J., Alexandrou, A. J., Fuller, M. D., et al. (2015). A novel selective and orally bioavailable Nav 1.8 channel blocker, PF-01247324, attenuates nociception and sensory neuron excitability. Br. J. Pharmacol. 172, 2654-2670. doi: 10.1111/bph. 13092

Pinilla, P. J., Hernández, A. T., Camello, M. C., Pozo, M. J., Toescu, E. C., and Camello, P. J. (2005). Non-stimulated $\mathrm{Ca}^{2+}$ leak pathway in cerebellar granule neurones. Biochem. Pharmacol. 70, 786-793. doi: 10.1016/j.bcp.2005.06.004

Pumain, R., Menini, C., Heinemann, U., Louvel, J., and Silva-Barrat, C. (1985). Chemical synaptic transmission is not necessary for epileptic seizures to persist in the baboon Papio papio. Exp. Neurol. 89, 250-258. doi: 10.1016/00144886(85)90280-8

Radzicki, D., Pollema-Mays, S. L., Sanz-Clemente, A., and Martina, M. (2017). Loss of M1 receptor dependent cholinergic excitation contributes to mPFC deactivation in neuropathic pain. J. Neurosci. 37, 2292-2304. doi: 10.1523/JNEUROSCI.1553-16.2017

Rehak, R., Bartoletti, T. M., Engbers, J. D., Berecki, G., Turner, R. W., and Zamponi, G. W. (2013). Low voltage activation of KCa1.1 current by Cav3-KCa1.1 complexes. PLoS One 8:e61844. doi: 10.1371/journal.pone. 0061844

Riley, M. R., and Constantinidis, C. (2016). Role of prefrontal persistent activity in working memory. Front. Syst. Neurosci. 9:181. doi: 10.3389/fnsys.2015. 00181

Rugiero, F., Mistry, M., Sage, D., Black, J. A., Waxman, S. G., Crest, M., et al. (2003). Selective expression of a persistent tetrodotoxin-resistant $\mathrm{Na}^{+}$current and NaV1.9 subunit in myenteric sensory neurons. J. Neurosci. 23, 2715-2725.

Rusakov, D. A., Harrison, E., and Stewart, M. G. (1998). Synapses in hippocampus occupy only $1-2 \%$ of cell membranes and are spaced less than half-micron apart: a quantitative ultrastructural analysis with discussion of physiological implications. Neuropharmacology 37, 513-521. doi: 10.1016/S0028-3908(98)00023-9

Sanchez-Vives, M. V., and McCormick, D. A. (2000). Cellular and network mechanisms of rhythmic recurrent activity in neocortex. Nat. Neurosci. 3, 1027-1034. doi: 10.1038/79848

Sangrey, T., and Jaeger, D. (2010). Analysis of distinct short and prolonged components in rebound spiking of deep cerebellar nucleus neurons. Eur. J. Neurosci. 32, 1646-1657. doi: 10.1111/j.1460-9568.2010.07408.x

Sayer, R. J., Schwindt, P. C., and Crill, W. E. (1990). High- and low-threshold calcium currents in neurons acutely isolated from rat sensorimotor cortex. Neurosci. Lett. 120, 175-178. doi: 10.1016/0304-3940(90)90031-4

Schubert, D., Martens, G. J., and Kolk, S. M. (2015). Molecular underpinnings of prefrontal cortex development in rodents provide insights into the etiology of neurodevelopmental disorders. Mol. Psychiatry 20, 795-809. doi: 10.1038/mp. 2014.147

Schubert, R., and Nelson, M. T. (2001). Protein kinases: tuners of the BKCa channel in smooth muscle. Trends Pharmacol. Sci. 22, 505-512. doi: 10.1016/s0165-6147(00)01775-2

Seamans, J. K., Nogueira, L., and Lavin, A. (2003). Synaptic basis of persistent activity in prefrontal cortex in vivo and in organotypic cultures. Cereb. Cortex 13, 1242-1250. doi: 10.1093/cercor/bhg094

Seamans, J. K., and Yang, C. R. (2004). The principal features and mechanisms of dopamine modulation in the prefrontal cortex. Prog. Neurobiol. 74, 1-58. doi: 10.1016/j.pneurobio.2004.10.002

Shipston, M. J., and Armstrong, D. L. (1996). Activation of protein kinase C inhibits calcium-activated potassium channels in rat pituitary tumour cells. J. Physiol. 493, 665-672. doi: 10.1113/jphysiol.1996.sp021413

Shu, Y., Hasenstaub, A., Badoual, M., Bal, T., and McCormick, D. A. (2003). Barrages of synaptic activity control the gain and sensitivity of cortical neurons. J. Neurosci. 23, 10388-10401.

Sivaramakrishnan, S., and Oliver, D. L. (2001). Distinct K currents result in physiologically distinct cell types in the inferior colliculus of the rat. J. Neurosci. 21, 2861-2877. 
Smith, M. R., Nelson, A. B., and Du Lac, S. (2002). Regulation of firing response gain by calcium-dependent mechanisms in vestibular nucleus neurons. J. Neurophysiol. 87, 2031-2042. doi: 10.1152/jn.00821.2001

Surges, R., Sarvari, M., Steffens, M., and Els, T. (2006). Characterization of rebound depolarization in hippocampal neurons. Biochem. Biophys. Res. Commun. 348, 1343-1349. doi: 10.1016/j.bbrc.2006.07.193

Szczepanski, S. M., and Knight, R. T. (2014). Insights into human behavior from lesions to the prefrontal cortex. Neuron 83, 1002-1018. doi: 10.1016/j.neuron. 2014.08.011

Szulczyk, B. (2016). Somatic and dendritic perforated-patch recordings reveal b-adrenergic receptor-induced depolarization in medial prefrontal cortex pyramidal neurons. Acta Neurobiol. Exp. 76, 158-164. doi: 10.21307/ane-20 17-015

Takahashi, R. H., Milner, T. A., Li, F., Nam, E. E., Edgar, M. A., Yamaguchi, H., et al. (2002). Intraneuronal Alzheimer a $\beta 42$ accumulates in multivesicular bodies and is associated with synaptic pathology. Am. J. Pathol. 161, 1869-1879. doi: 10.1016/s0002-9440(10)64463-x

Tennigkeit, F., Schwarz, D. W., and Puil, E. (1998). Modulation of bursts and high-threshold calcium spikes in neurons of rat auditory thalamus. Neuroscience 83, 1063-1073. doi: 10.1016/s0306-4522(97) 00458-2

Thierry, A. M., Gioanni, Y., Degenetais, E., and Glowinski, J. (2000). Hippocampoprefrontal cortex pathway: anatomical and electrophysiological characteristics. Hippocampus 10, 411-419. doi: 10.1002/1098-1063(2000)10:4<411::aidhipo7>3.0.co;2-a

Tian, Y., and Laychock, S. G. (2001). Protein kinase C and calcium regulation of adenylyl cyclase in isolated rat pancreatic islets. Diabetes 50, 2505-2513. doi: 10.2337/diabetes.50.11.2505

Timofeev, I., Bazhenov, M., Sejnowski, T., and Steriade, M. (2002). Cortical hyperpolarization-activated depolarizing current takes part in the generation of focal paroxysmal activities. Proc. Natl. Acad. Sci. U S A 99, 9533-9537. doi: 10.1073/pnas.132259899

Timofeev, I., Grenier, F., and Steriade, M. (1998). Spike-wave complexes and fast components of cortically generated seizures. IV. Paroxysmal fast runs in cortical and thalamic neurons. J. Neurophysiol. 80, 1495-1513. doi: 10.1152/jn. 1998.80.3.1495

Turner, R. W., and Zamponi, G. W. (2014). T-type channels buddy up. Pflugers Arch. 466, 661-675. doi: 10.1007/s00424-013-1434-6

Uchino, S., Wada, H., Honda, S., Hirasawa, T., Yanai, S., Nakamura, Y., et al. (2003). Slo2 sodium-activated $\mathrm{K}^{+}$channels bind to the PDZ domain of PSD-95. Biochem. Biophys. Res. Commun. 310, 1140-1147. doi: 10.1016/j.bbrc.2003. 09.133

Valenti, O., and Grace, A. A. (2009). Entorhinal cortex inhibits medial prefrontal cortex and modulates the activity states of electrophysiologically characterized pyramidal neurons in vivo. Cereb. Cortex 19, 658-674. doi: 10.1093/cercor/bhn114

Van Hook, M. J., and Berson, D. M. (2010). Hyperpolarization-activated current $\left(I_{\mathrm{h}}\right)$ in ganglion-cell photoreceptors. PLoS One 5:e15344. doi: 10.1371/journal. pone.0015344

van Welie, I., and du Lac, S. (2011). Bidirectional control of BK channel open probability by CAMKII and PKC in medial vestibular nucleus neurons. J. Neurophysiol. 105, 1651-1659. doi: 10.1152/jn.00058.2011
Vassilev, P. M., Mitchel, J., Vassilev, M., Kanazirska, M., and Brown, E. M. (1997) Assessment of frequency-dependent alterations in the level of extracellular $\mathrm{Ca}^{2+}$ in the synaptic cleft. Biophys. J. 72, 2103-2116. doi: 10.1016/s00063495(97)78853-2

Volkow, N. D., Koob, G. F., and McLellan, A. T. (2016). Neurobiologic advances from the brain disease model of addiction. N. Engl. J. Med. 374, 363-371. doi: 10.1056/NEJMra1511480

Wang, X. J., Golomb, D., and Rinzel, J. (1995). Emergent spindle oscillations and intermittent burst firing in a thalamic model: specific neuronal mechanisms. Proc. Natl. Acad. Sci. U S A 92, 5577-5581. doi: 10.1073/pnas.92.12.5577

Wilson, C. J., and Kawaguchi, Y. (1996). The origins of two-state spontaneous membrane potential fluctuations of neostriatal spiny neurons. J. Neurosci. 16, 2397-2410.

Yaari, Y., Konnerth, A., and Heinemann, U. (1983). Spontaneous epileptiform activity of CA1 hippocampal neurons in low extracellular calcium solutions. Exp. Brain Res. 51, 153-156. doi: 10.1007/bf00236813

Yamamoto, K., Ueta, Y., Wang, L., Yamamoto, R., Inoue, N., Inokuchi, K., et al. (2011). Suppression of a neocortical potassium channel activity by intracellular amyloid- $\beta$ and its rescue with Homer1a. J. Neurosci. 31, 11100-11109. doi: 10.1523/JNEUROSCI.6752-10.2011

Yu, Y. Q., Xiong, Y., Chan, Y. S., and He, J. (2004). Corticofugal gating of auditory information in the thalamus: an in vivo intracellular recording study. J. Neurosci. 24, 3060-3069. doi: 10.1523/JNEUROSCI.4897-03.2004

Zamponi, G. W., Lory, P., and Perez-Reyes, E. (2010). Role of voltage-gated calcium channels in epilepsy. Pflugers Arch. 460, 395-403. doi: 10.1007/s00424009-0772-X

Zhang, X. F., Shieh, C. C., Chapman, M. L., Matulenko, M. A., Hakeem, A. H., Atkinson, R. N., et al. (2010). A-887826 is a structurally novel, potent and voltage-dependent $\mathrm{Na}_{v} 1.8$ sodium channel blocker that attenuates neuropathic tactile allodynia in rats. Neuropharmacology 59, 201-207. doi: 10.1016/j. neuropharm.2010.05.009

Zheng, N., and Raman, I. M. (2009). Ca currents activated by spontaneous firing and synaptic disinhibition in neurons of the cerebellar nuclei. J. Neurosci. 29, 9826-9838. doi: 10.1523/JNEUROSCI.2069-09.2009

Zhou, X. B., Wulfsen, I., Utku, E., Sausbier, U., Sausbier, M., Wieland, T., et al. (2010). Dual role of protein kinase C on BK channel regulation. Proc. Natl. Acad. Sci. U S A 107, 8005-8010. doi: 10.1073/pnas.0912029107

Zylberberg, J., and Strowbridge, B. W. (2017). Mechanisms of persistent activity in cortical circuits: possible neural substrates for working memory. Annu. Rev. Neurosci. 40, 603-627. doi: 10.1146/annurev-neuro-070815-014006

Conflict of Interest Statement: The authors declare that the research was conducted in the absence of any commercial or financial relationships that could be construed as a potential conflict of interest.

Copyright (C) 2018 Kurowski, Grzelka and Szulczyk. This is an open-access article distributed under the terms of the Creative Commons Attribution License (CC BY). The use, distribution or reproduction in other forums is permitted, provided the original author(s) and the copyright owner are credited and that the original publication in this journal is cited, in accordance with accepted academic practice. No use, distribution or reproduction is permitted which does not comply with these terms. 